\title{
Las imágenes del espectáculo: apuntes en torno a Verdi y la escenografía (I)
}

Juan P. Arregui

El autor plantea la siempre fascinante temática de la escenografía a través del ejemplo concreto de los montajes teatrales diseñados para la puesta en escena de las grandes óperas de Giuseppe Verdi. Sin dejar de insistir en la naturaleza compleja de estos montajes, el trabajo abunda en la problemática intrinseca del género, planteando su relación con la pintura de Historia, los ciclos narrativos y la pintura decorativa del siglo $X I X$, ponderándose los resultados logrados como ejercicio de integración entre distintos campos artísticos coetáneos.

This article is about scenographies created for Verdi's operas and their implications with another contemporary artistic subjects, connected and integrated with the view of History, narrative cycles and scene and decorative paintings of XIX century

De entre todos los grandes compositores operísticos del siglo XIX quizá sea el caso de Verdi -junto con Richard Wagner- el más conocido en cuanto a su implicación con compendios teróricoscenográfico. A pesar de que no sistematizó su pensamiento en significativo de la imagen la preocupación del maestro italiano por la calidad y el valor sus obras, el peso del elemento, sus ideas y opiniones sobre el montaje teatral de cuidado e interés que demostró visual en el mismo proceso de composición o el ha sido puesto de manifiesto en numerante a la realización práctica de sus óperas estudios particulares.

Razones de variada índole han concurrido al efecto. Por un lado la evolución de los trabajos sobre historia del teatro, historia del arte y, evidentemente, musicologia, cada vez más interesados en aquellos argumentos que conforman, determinan,

ARREGUI, Juan: "Las imágenes del espectáculo: apuntes en torno a Verdi y la escenografía (I)", en Boletín de Arte $\mathrm{n}^{\circ}$ 25, Universidad de Málaga, 2004, págs. 149-179. 
precisan o construyen la dimensión espectacular del producto dramático: factores y procesos de realización, la proyección instrumental de las obras o la corresponsabilidad sinérgica de los diferentes dominios del arte en tanto que sistemas de significación y comunicación concurrentes en el espectáculo.

La renovada vocación hacia tales elementos ha favorecido investigaciones concernientes a diversos aspectos de la dramaturgia, la relación vinculante entre creación y representación, la actividad concreta de coliseos y de escuelas escenográficas, los mecanismos particulares de producción y realización, el proceder de pintores teatrales y decoradores concretos, etc., en los que Italia ha tenido un protagonismo innegable y de los que se está beneficiando la historiografía crítica de la ópera italiana: la mediazione tra il punto di vista della musica e il punto di vista della parola è operata dallo spettacolo, naturale definizione del melodramma'. Dentro de tal ámbito, la producción verdiana, por su propia trascendencia, extensión, difusión y magnitud intrinseca ha sido, necesariamente, sujeto propicio al tiempo que objeto reiterado y no pocas veces substancial en este tipo de análisis.

Por otro lado -y en paralelo a la evolución de tales intereses ${ }^{2}$ - no ha de olvidarse la labor de instituciones como el Istituto Nazionale di Studi Verdiani de Parma ${ }^{3}$, cuya actividad específica ha favorecido un gradual desarrollo de los estudios en tomo al Maestro de Busseto, revelando desde muy pronto un significativo favor hacia el examen de los componentes escénicos de su catálogo lírico e impulsando buen número de ensayos que han ido viendo la luz en diversas publicaciones ${ }^{4}$. Tal disposición ha conocido derivaciones de notable alcance como la dedicación del congreso internacional de estudio celebrado en 1994 a La realización escénica del espectáculo verdiano ${ }^{5}$ y la publicación de las subsecuentes $\operatorname{actas}^{6}$ o la exposición

1 PORTINARI, F.: "Pari siamo. Sulla struttura del libretto romantico". En ll Melodramma italiano dell'Ottocento. Studi e Ricerche per Massimo Mila. (G. Pestelli (ed.). Torino: Giulio Einaudi Editore, 1977): 545-566, 547 (reprod. y resumido en Scene e figure del teatro italiano. Quaderni del Teatro Municipale "R. Valli" I (1981), págs. 105-119).

"Recordemo"s al respecto, en el seno de las 'Celebrazioni Nazionali Verdiane' de 1951, la iniciativa de una primera Mostra Nazionale di Scenografia Verdiana (Parma: Ridotto del Teatro Regio, settembre-ottobre 1951) y la edición de su correspondiente catálogo (ZONI, B. y SCACCAGLIA, A. (coms.): Parma: Società Tipografica Editoriale, 1951)

3 Fundado en 1960 como asociación y convertido en Instituto en 1963. Para más información sobre este centro vid LA FACE BIANCONI, G.: "Nel nome del Maestro. L'Istituto nazionale di studi verdiani". Amadeus (mayo 1996), págs. 46-48, así como la página que la Fondazione Verdi Festival y la Provincia de Parma dedican a las instituciones culturales vinculadas al compositor (www.giuseppeverdi.it/rete/istituzioni).

* A este respecto, y para una actualización bibliográfica regular sobre la vida, la obra y cualquier aspecto relacionado con el compositor resulta indispensable la consulta de los apéndices "Bibliografia verdiana" incluidos en los números de la revista Studi Verdiani (Parma: apéndices "Bibliografia verdiana incluid

5 La realizzazione scenica dello spettacolo verdiano. Congresso internazionale di studi. Parma: Teatro Regio-Conservatorio de Musica "A. Boito", 28-30 settembre 1994. 
monográfica "Sorgete! Ombre serene!" L'Aspetto visivo dello spettacolo verdiano con verdi" de 1995 recayó titulado La scenografia verdiana fra due, sobre un trabajo de la Dra. Olga Jesurum comprobarse así la creciente estima de locoli: ieri e oggi, todavía inédito. Puede extratextuales léase texto en sentima de los especialistas hacia los ingredientes dramática de Verdi, que, sustentada en un cada vez como musical en la producción estudiadas ( $y$ convenientemente publicadas $y$ más amplio repertorio de fuentes correspondencia del maestro, bocetos escenos y analizadas muchas de ellas: reposiciones, disposiciones escénicas f lonográficos para los estrenos absolutos y materiales de los que nos serviremos ha generado un considerable corpus de aproximación.

\section{LOS ARBITRIOS DEL MELODRAMA: UN CONTEXTO MATERIAL Y FORMAL}

Giuseppe Verdi desembarca en la escena lírica italiana en 1839 con su primera ópera, Oberto, conte di San Bonifacio (17-XI-1839), estrenada en la Scala de Milán uno de los más importantes teatros líricos del momento, referencia ineludible a comienzos del siglo XIX por el nivel de sus producciones y la categoria de los profesionales que sustentaban su escenario. Milán, junto con Nápoles y Venecia, han de los primeros como los centros predominantes en la producción operistica italiana proyectará sobre el resto de la centuria ${ }^{8}$, cuya tradición -en todos los órdenes- se de novedades extranjeras, la peninsula sirviendo además de cauce en la difusión Paris ${ }^{9}$. En cualquier caso a cuya vanguardia en materia escénica parece hallarse presenta, si no unas cara la decada de 1840 la escenografía operistica europea como resultado de distintos facticas si unas directrices definitorias comunes que, "PETROBELLI, P. y DELLA SETA, F: La realizzazione scenica dello spettacolo verdiano, Parma,
Istituto Nazionale di Studi Verdiani, 1996.

"PETROBELLI, P; DI GREGORIO CASATI, M. y JESURUM, O. (eds.): "Sorgete! Ombre serene!" LAspetto visivo dello spettacolo verdiano. Parma: Istituto Nazionale di Studi Verdiani, 19962. in Italia: $1800-1820^{\prime \prime}$. En Muszazione, gestione, politica teatrale e repertori operistici a Napoli e (eds.). Firenze: L. S. Olschki, 1983), págs Napoli dal XV al XIX secolo (L. Bianconi y R. Bossa Aunque a lo largo del siglo

ciudades italianas, no perderán proda apreciar una menor de primacía de las mencionadas verdianos, en el que, a pesar de una evonismo y así lo atestigua el registro de estrenos Cairo y de Trieste a San Petersburgo), de sus veintion geográfica (que abarca de Rímini a El assoluta o en versión revisada- en La Scala de Milán, óperas, diez se estrenarán -en prima Nápoles y cuatro en París. 
El siglo XIX demarca el umbral de una cultura europea que progresivamente afianza los limites de su alcance internacional, situación de la que participan los engranajes que mueven la máquina del espectáculo lírico. Los coliseos se normalizan según unas pautas que, centradas en la resolución satisfactoria de los obstáculos interpuestos por exigencias técnicas constantes, facilitan la estandarización de la realización escénica y por tanto su reproducción. Este factor resuita de innegable importancia dada la vigorosa circulación de obras y producciones a lo largo de la centuria, auspiciada tanto por el incremento y diversificación de las audiencias cuanto por la inserción del teatro entre las competencias empresariales como operación comercial. No parece casual el hecho de que los derechos de autor sean reconocidos en Italia precisamente en esta época, al año siguiente del estreno de Oberto, en 1840\%; el teatro musical, diseñado para satisfacer los gustos y aspiraciones estéticas de una clase media en expansión, deberá basar la organización de su sistema productivo en función de los principios tutores de una gradual industrialización, haciendo frente a las premisas de un repertorio progresivamente establecido (y constantemente interpretado) y adecuándose a una demanda cada vez más exigente y en continuo crecimiento.

El diseño edilicio del teatro incorpora los estatutos de lo que se ha reconocido como gran coliseo burgués: una articulación de diversos materiales y componentes (arquitectónicos, pictóricos, ornamentales, espaciales, ópticos, acústicos, mecánicos, protocolarios, etc.) destinados a la representación que durante la primera mitad de la centuria quedan estipulados y cualificados, deviniendo una "indiscutida convención cultural"". El edificio teatral decimonónico por antonomasia es el modelo allitaliana, un producto elaborado y reelaborado sobre su propia histéresis cultural en tanto material arquitectónico que depende de una historia previa, iniciada en las experiencias seicentistas y difundida con modificaciones durante el siglo XVIII, convirtiéndose a partir de entonces en forma mentis hegemónica. Como resultado, el universo artificial del teatro llega a ser un'unità morfologica al di là delle varietà architettoniche $^{12}$ que deviene elemento activo de la expresión artistica, ya sea en su configuración física ya en su capacidad para determinar la fruición del público que lo ocupa a través de las diversas categorías expresivas que interactúan (visión y figuración, volumen y ambiente). Un patrón que refrendará su validez, precisamente, sobre los requerimientos del espectáculo lírico ${ }^{13}$. Dicha estructura orgánica, además de constituirse en un espacio emblemático de cimentación social de la cultura burguesa ${ }^{14}$ decreta las propias condiciones de realización del espectáculo, diseñado

${ }^{10}$ Cfr.: ROSSELLI, J.: "Verdi e la storia delia retribuzione del compositore italiano". Studi Verdiani 2 (1983), págs. 11-28.

" CRUCIANI, F y SERAGNOLI, D. (dirs.): Teatro italiano nel Rinascimento. Bologna: Il Mulino, 1987, págs. 347-48.

${ }^{12}$ BANU, G.: II rosso e oro. Una poetica della sala allitaliana. Milano: Rizzoli, 1990, págs.69.

13 CRUCIANI, F: Lo Spazio del teatro. Roma-Bari: Editori Laterza, 1999, págs.12 y 24.

i TAFUR, M.: Teatri e Scenografie. Milano: Serv. Publ. Touring Club Italiano, 1976, págs.35-36. 
éste en función de las competencias y posibilidades del entorno material que lo acoge. Resulta innegable la adecuación de la correspondencia entre dicha morfología de teatro y la concepción escénica fundada en el ilusionismo pictórico y su tecnologia, sancionando reciprocamente ambos extremos su respectiva validez

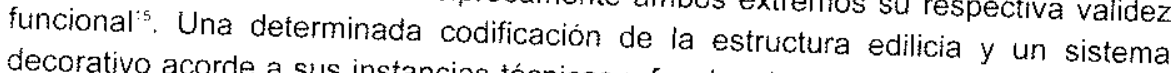
decorativo acorde a sus instancias técnicas y funcionales, que el lugar teatral, a un tiempo, impone y requiere:

Tales instancias administran los cimientos de lo que será el ejercicio escenográfico distintivo y prevalente del modo teatral occidental hasta el $\mathrm{s}$. XX'; un sistema desarrollado durante la experiencia barroca y madurado durante el XVIII que adquiere un altísimo grado de perfección a finales de este siglo, cuando la práctica totalidad de sus componentes ha alcanzado una definición última a través de la utilización sistemática y prácticamente exclusiva de elementos bidimensionales, mediante la articulación de distintas piezas armadas de tela pintada, para la construcción y recreación de localizaciones y ambientes sobre el escenario. En términos generales, y siguiendo a Pierre Sonrel, podría afirmarse que, en el transcurso del Ochocientos, la evolución escenográfica consiste más en variaciones estéticas, corolario de las ideas y del gusto de cada momento, que en modificaciones estructurales de la escena o de la maquinaria, que no harán sino adaptarse a los progresos instrumentales, actualizándose e incorporando adelantos tecnológicos
puntuales:s.

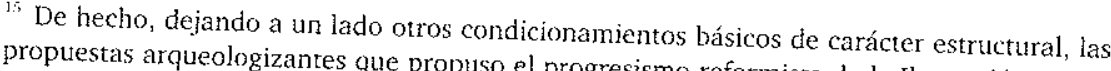
propuestas arqueologizantes que propuso el progresismo reformista de la Ilustración no realizado por el arquitecto Brückwald en 1876 . Wagner en el Festpielhaus de Bayreuth, de que el diseño en hemiciclo era difícilmente compatibles precedentes de Semper) a causa fundaba el ejercicio dramático. Será ésta precimpatible con el escenario ilusionista en que se por aquellos teóricos que en el XIX esta, precisamente, una de las razones razones aducidas como Quatremère de Quincy ("Théâtre", en Diction teatro en cuanto displina arquitectónica Clerc, 1832, ad voc. ) o Julien Guadet (Eléments onnaire Historique d'Architecture. Paris: A. Le I'École nationale et Spéciale des Beaux-Arts ents et Théorie de l'Architecture, cours professé à 1901), t. III, págs. 76 y 84) entre otros.

16 No en vano, cuando Adolphe Appia (figura dererminante en la evolución teatral del siglo XX)
se proponga una regeneración trascendental de "contre le théâtre à l'italienne trascendental de los usos escénicos establecidos se revolverá cual propondrá una "réforme radicale de l'architecturenction de la salle et de la scène" ante lo générale du décor de théâtre de 1870 à 1914 . ${ }_{17}$ Todavía en 1958 José Mestres Cabanes y Andrés Vds. du CNRS, 1975, págs. 262. decorados", al describir los elementos que Andrés Vallvé Ventosa, en su artículo "Los preponderancia de los elementos bidime conforman la escenografía tradicional, se basan en la dicho repertorio material (vid.: DÍAZ PLAJA G. (dir), Barcelona: Ed. Noguer, 1958, págs PLAJA, G. (dir), Enciclopedia del Arte Escénico.

is SONREL, P. Traité de scénographie. Évolution du matériel scènique. Inventaire et mise en
oeuvre du matériel scènique actuel Technique de l'etabissem théâtrale. Autres scènes en usage. Paris: O. Leutier detablissement des décors. Perspective
} 
La concepción del escenario no sólo refleja la dinámica social en que se inserta, sino que también establece sus fundamentos organizativos -a todos los niveles- bajo sus principios y directrices, es decir, aquéllos de una gradual mecanización. Efectivamente, la integración de nuevas tecnologías en la producción artística fue un factor decisivo en el proceso de definición del espacio escénico, que debía ser capaz de albergar y explotar todas sus posibilidades. Ello implicaba un aumento de dimensiones, imprescindible alla grandiosità degli spettacoli ${ }^{19}$, tanto en lo referente a aquellos espacios aledaños que habilitaban la instalación y el funcionamiento de la maquinaria y el aparataje teatral como en lo relativo a la superficie del mismo (que crece fundamentaimente en anchura respecto de sus precedentes barrocos):

[Aujourd'hui] I'impression produite par les décorations n'est pas rigoureusement liée à la distance à laquelle est placée la toile de fond (...). Mais, si la scène n'a pas besoin d'être tres profonde, elle ne saurait au contraire être trop large. Les couloirs de circulation où doivent se masser les acteurs, les choristes et les comparses, puis les tas et dépôts de décors, tout cela exige une grand place, un grand espace, quie est bien rarement accordé, et ce n'est pas seulement au point de vue de la circulation et des agencements des tas que la scène doit être large, c'est encore et surtout peut-être au point de vue de la décoration" escribia en 1871 Charles Garnier, arquitecto responsable del nuevo Théâtre de l'Opéra parisino, emblema del gran teatro burgués decimonónico ${ }^{20}$.

No resulta éste un argumento a menospreciar, pues la capacidad y compostura del escenario constituyen las bases del soporte técnico en que se asienta la operatividad de los espacios que acogen el espectáculo y las posibilidades instrumentales en que éste se apoya. Compositores y dramaturgos eran conscientes de tales condiciones, cuyas características redundaban físicamente en el desarrollo escénico de la acción y se proyectaban, por tanto, en la génesis de las obras.

De hecho Roger Parker ha puesto de manifiesto esta tesis entre los motivos que incidieron en el cambio de dirección experimentado en la inicial carrera de Giuseppe Verdi con la composición de Ernani (1844), un drama lírico centrado en los conflictos personales, con el que se adentra en la via de la introspección psicológica y la confrontación de caracteres, alejandose del 'genere grandioso' por donde habian transitado sus dos óperas inmediatamente anteriores (Nabucco e / Lombardi alla

${ }^{19}$ LANDRIANI, P: Osservazioni dell'Architetto e Pittore Scenico Signor Paolo Landriani su L'Imp. R. Teatro Alla Scala in Milano e sopra alcuni articoli de] saggio di M. Patte. En Storia e descrizione de' principali teatri antichi e moderni corredata di tavole col saggio dell'architettura teatrale illustrato con erudite osservazioni del chiarissimo architetto e pittore scenico Paolo Landriani. Milano: Ferrario, 1830 (Reed.: Biblioteca Musica Bononiensis, Sezione III, N. 49. Bolonia: Arnaldo Forni Editore, 1977), págs. 315-369, 340.

${ }^{20}$ GARNIER, C.: Le Théâtre. Paris: Librairie Hachette \& Cie., 1871 (reed.: G. Banu y M. Kahane (eds.). Charles Garnier. Le Théâtre. Arles: Actes Sud, 1990), pág. 221. 
prima crociata) dado que éstas fueron creadas para el Teatro alla Scala, uno de los mayores escenarios de Italia -y por lo tanto adecuado a los dilatados efectos corales de tales obras- mientras que aquélla debía acomodarse a la atmósfera más intima del Teatro La Fenice de Venecia ${ }^{21}$. Una razón ya aducida por sus contemporáneos para explicar la tibia acogida de los titulos 'scaligeros' en otros teatros italianos, tal y como reseña una crítica del Allgemeine musikalische Zeitung de 1844: "Gli amici del Sig. Verdi, i quali non arrivano a comprendere come i suoi Nabucco e Lombardi, che fecero un grande furore a Milano, possano naufragare altrove, danno l'unica e sola colpa al fatto che gli altri teatri sono molto più piccoli e non hanno la possibilità di pressentare le masse della grande Scala di Milano"2z

Paralelamente, y al margen de particulares opciones estilisticas o conceptuales en la elaboración de un entorno visual para el texto lírico-dramático, resulta patente el hecho de que a partir de los progresos del romanticismo el programa iconográfico que coloniza los escenarios se transforma en la misma medida en que lo hace su tratamiento plástico, acrecentándose la explotación de toda suerte de procedimientos destinados a potenciar el ilusionismo escénico. La escena se concibe como una caja óptica en donde se integran las representaciones pictórico-perspectivas apoyadas tanto en sus propios valores plásticos como en los efectos de la iluminación artificial, un aspecto determinante en la configuración de la visualidad teatral del ochocientos a partir de la revolución que supuso la implantación en los teatros de la luz de gas (y posteriormente eléctrica).

Favorece este proceso la tendencia a resolver la mayor parte de la escena con telones de fondo, bastidores y rompimientos en la linea de enormes cuadros alusivos que, como ha señalado André Chastel, denuncian la pasión decimonónica por la pintura ${ }^{23}$ : "ora si devono studiare di più il dettaglio, gli effetti di chiaroscuro e contrasti di colore, in una parola la verità, di modo che ora lo scenografo si avvicina di più al pittore di quadri" escribió a finales de siglo el decorador teatral Pietro Bertoja ${ }^{24}$

El cuadro escénico constituye una realidad imperativa que determina las relaciones de conexión entre sala y escenario, supone la apertura del volumen escénico al espacio espectatorial, descubriendo un universo que delimita idealmente. De esta manera el área de la representación deviene un área separada del resto de la vida social y pasa

\footnotetext{
"Cfr: PARKER, R.: "Ernani". En The New Grove Dictionary of Opera (S. Sadie (ed.). London:
Macmillan Publishers Limited. 1992): ad vocem.

Allgemeine musikalische Zeitung XLVI-7 (14-I1-1

di critiche e cronache verdiane dalla Allgeme-11-1844). Reprod. trad. por CONATI, M.: "Saggio

Melodramma... Op. cit., págs. 13-43, 22 .

CHASTE A. Lima

14 BERTOJA, P: Sullage dans le miroir. Paris: Gallimard, 1980, pág. 152.

Correr, Mss. Cit por MURARO, M. T.: "Nuovi album dei bozzetti). Venezia: Civico Museo

Venezia". En La realizzazione... Op. cit., págs. 83-108, 90 .
} 
a ser el espacio de proyección de la intimidad del espectador individual, singularizando al escenario como el ámbito del bueno, real y bello en donde la burguesia podía ver su identidad garantizada ${ }^{25}$. Resulta sintomática la vigencia que esta forma de entender el escenario, y por tanto de diseñar el decorado como un cuadro, mantendrá hasta el siglo $X X$. El proceso de configuración de la escena como un cubo cerrado y autónomo respecto a la sala -iniciado por la introducción del arco de embocadura, impulsado por la experiencia bibienesca y defendido por la ilustración $n^{26}$-, se radicaliza en estos momentos. El ámbito de la ficción se disocia drásticamente de la esfera del público ${ }^{27}$, concibiéndose como terreno propio de la teatralidad concreta (entendiendo por ello la actividad que constituye la representación ${ }^{28}$ ) única y exclusivamente el área confinada en el escenario. La idea del cuarto muro invisible que termina de aislar el escenario (bandera del posterior naturalismo), deviene fundamento sustancial en la tentativa de reproducir fragmentos de la realidad dentro de la caja escénica, principio sobre el que se establece la escenografia teatral decimonónica, apoyándose en toda suerte de artificios para recrear 'el natural'.

Un principio éste que centra las preocupaciones de autores tan implicados en la escenificación de sus obras como el que nos atañe en estas páginas; en efecto, el propio Giuseppe Verdi pondrá en tela de juicio la consuetudinaria articulación del teatro allitaliana, censurando la existencia de los palcos-proscenio ${ }^{29}$-una de las evoluciones de la embocadura inherentes al desarrollo del tipo edilicio ${ }^{30}$ - y criticando

${ }_{25}$ FISCHER-LICHTE, E.: Semiótica del Teatro. Madrid: Arco/Libros, 1999, pág. 200 y 204. 26 "A partir du premier quart du XVIIIe siècle, l'art théâtral commença déjà à modifier ses techniques dans les sens des transformations définitives qu'il devait subir à l'époque romantique", ALLEVY, M-A.: La mise en scène en France dans la première moitié du dixneuvième siècle. Paris: Librairie E. Droz, 1938 (Reed. Genève: Slatkine Reprints, 1976), pág. 7.

${ }^{27}$ Se rechaza de plano cualquier tentativa de acercamiento al principio especular de mutua correspondencia entre sala y escenario -o lo que es lo mismo, entre acción fingida y realidad institucional- que autorizaba la continuidad de áreas del espacio coextenso al compenetrar ambos sectores en esa mágica y engañosa transferencia entre certidumbre y fantasía que era ingrediente constitutivo del teatro barroco. Cfr.: P. ARREGUI, J.: "Pintura, mecánica, teatro y corte en el XVII tardío. En torno a la realización escenográfica del teatro cortesano de los últimos Austrias españoles". En De una Dinastia a otra. Artes y Letras en las Cortes de España y Austria/ 1700 Von einer Dynastie zur Anderen. Künste und Literaturam Österreichischen und am Spanischen Hof. ( $\mathrm{M}^{\mathrm{a}}$. A. Virgili, K. F. Rudolf y J. P. Arregui (eds.). Madrid: Universidad de Valladolid-Instituto Histórico Austríaco): en prensa.

${ }^{28}$ UBERSFELD, A.: Semiótica teatral. Signo e imagen 18. Madrid, Cátedra, 1989, pág. 110.

29 "(...) Questi piccoli perfezionamenti apriranno poi la strada ad altre innovazioni che verranno certamente un giorno, e fra queste quella di togliere dal palcoscenico i palchetti degli spettatori, portando il sipario alla ribalta". Carta de Verdi a G. Ricordi (10-VII-1871). En OBERDOFER, A. (ed.): Giuseppe Verdi. Autobiografia dalle lettere. Milano: Rizzoli, 1951 (Nuova edizione, interamente riveduta con annotazioni e aggiunte a cura di Marcello Conati. Milano: Rizzoli, 1981), págs. 474-76.

${ }^{30}$ Cfr: LECLERC, H.: Les origines italiennes de l'Architecture théâtrale moderne. Paris: E. Droz, 1946, pág. 200.

\section{$\overline{156}$}


la establecida posición de la orquesta ${ }^{31}$ en orden a la coherencia de una ilusión escénica que se pretendia absoluta: (...) rendere l'orchestra invisibile (...). Pare impossibile che al giorno d'oggi si tolleri di vedere il nostro meschino frack, e le cravattine bianche, miste per es. ad un costume Egizio, Assirio, Druidico, etc., etc., e di vedere, inoltre, la massa d'orchestra, che è parte del mondo fittizio, quasi nel mezzo della platea fra il mondo dei fischianti o dei plaudenti. Aggiungete a tutto questo lo sconcio di vedere per aria le teste delle arpe, i manichi dei contrabassi, ed il molinello del Direttore d'orchestra (...), haciéndose eco explícito de las reflexiones wagnerianas (Quest'idea non è mia, è di Wagner: è buonissima ${ }^{32}$ ).

No debe olvidarse, por último, la decisiva influencia que Francia detentó sobre la escenografia europea decimonónica; concretamente la supremacía de la Opéra de Paris, gravó sobre el conjunto de teatros contemporáneos debido no sólo a su importancia social (la capital francesa era reconocida como "la capitale artistique du monde entier ${ }^{\prime 33}$ ) sino también a las condiciones materiales con que funcionaba. La frase de Leveaux il n'y a qu'un Opéra dans le monde entier ${ }^{34}$ resume una situación explicitamente reconocida por el propio Verdi quien, todavia a finales de siglo, se referia a éste como il maggior teatro d'Europa ${ }^{35}$. Si bien es cierto que los profesionales italianos continuaban manteniendo un innegable prestigio internacional ${ }^{36}$ y su producción hacía gala de cierta especificidad expresiva, no to es menos el hecho de que a partir de las primeras décadas del XIX la práctica francesa se impuso al resto de las tradiciones escenográficas bajo la égida ejemplar de las realizaciones de los grandes teatros parisinos ${ }^{37}$ y su sistema de producción: considerables medios técnicos y económicos favorecidos por la protección estatal, un procedimiento ejecutivo centralizado a partir de la ordenación jerárquica de funciones

\footnotetext{
${ }^{31}$ Con respecto a la problemática relacionada con la posición de la orquesta en el teatro Cfr PIRROTTA, N.: "Il luogo dell'orchestra". En Illusione e pratica teatrale: proposte per una lettur Povoledo (eds.). Vicenza intermedii fiorentini allopera comica (F. Mancini, M. T. Muraro y E. orquestas decimonónicas Vid. PIPER 1975), págs. 137-145. Sobre otros aspectos de las nell'Ottocento. Bilanicas Vid.: PIPERNO, F.. "Le orchestre dei teatri đ'opera italiani

32 Carta de Verdi a G. Ricordi (10-VII-1871). Ena". Studi verdiani 11 (1996), págs. 119-221. Autobiografia...Ob. cit. págs. 474-76.

33 MALLIOT, A.-L.: La Musique au thêâtre. Paris: Amyot, 1863, pág. 312.

${ }^{34}$ LEVEAUX, A.: "Le public des théâtres de Paris". Revue du théâtre (13-IX-1987), págs. 659. 326.

Durante el XIX se continúan 'exportando' escenógrafos italianos: a partir de 1813 está igual manera que Cesare en Francia de Cesare Carnevali (quien también trabaja en España, de adelante Domenico Ferri Carnevali y los hermanos Giuseppe y Francesco Lucini), y más

Busato, Bernardo Bonardi y hijo Augusto quien, junto con colaboradores de la talla de Giorgio segunda mitad del ochocientos 37 Cfr. POUGIN, A. "Decortos des arts qui s'y rattachent décoration". En Dictionnaire historique et pittoresque du théâtre et
} 
y responsabilidades así como la regulación metódica de las diversas actividades que intervienen en el espectáculo.

La voluntad de "personalizar" las puestas en escena de cada obra, individualizando la escenificación de los títulos representados, venía a combatir la acostumbrada rutina de los decorados de dotación, lo que Navascués Palacio ha dado en llamar juegos mínimos ${ }^{38}$. Éstos consistían en una colección decorativa genérica e intercambiable, acomodable sin grandes dificultades a diferentes obras, que servia para caracterizar visualmente textos distintos dentro de una serie de ambientaciones comunes que se repetian a menudo. Se trataba de abarcar el mayor número de localizaciones posibles según una tipología establecida por las exigencias de la escena de la época: salón de palacio, jardín, gabinete cerrado, casa pobre, campiña, etc., lo que auspiciaba continuas reutilizaciones de las mismas escenografías en muchas ocasiones sin adherencia significativa alguna con respecto al drama que respaldaban ${ }^{39}$. Precisamente los progresos en el concepto de un sistema de producción artístico y los esfuerzos de coordinación en la conquista de un resultado globalmente satisfactorio y acorde a la voluntad original de los creadores del espectáculo se fija en Francia a través de la publicación de cahiers y livrets de mise en scène: aplicación práctica de la ya aludida política empresarial en la gestión del espectáculo operístico que en sus exigencias de replicabilidad sistemática precisaba consolidar -de forma vinculante y rigurosa- opciones canónicas para la escenificación del repertorio y facilitar asi sucesivas representaciones haciendo posible su transferencia a cualquier escenario. Esta medida será asumida como práctica ordinaria en París ya desde la década de $1830^{40}$, desde donde se irá extendiendo a otros paises europeos.

Sin embargo la readaptación de decorados se mantendrá como una constante en el ejercicio teatral decimonónico. Sabemos por el propio Verdi que en el estreno de Nabucco, a pesar del effetto cosi grande que obtuvieron algunos de sus cuadros (la prima scena del tempio), la ópera se representó con decoraciones vecchie, riaccomodate sobre escenas anteriores de Peroni ${ }^{4}$. Incluso en la Ópera de Paris,

\footnotetext{
3R NAVASCUÉS PALACIO, P: "las máquinas teatrales: arquitectura y escenografía". En Arquitectura teatral en España (Catálogo de la exposición de la Dirección General de Arquitectura y Vivienda, Diciembre 1984-Enero 1985. Madrid: Servicio de Publicaciones MOPU, 1985), págs. 53-63.

39 ALONGE, R.: Teatro e spettacolo nel secondo Ottocento. Roma: Gius. Laterza \& Figli, 1997, págs. 15 y ss.

1:5 COHEN, H. R. y GIGOU, M.-O.: "La conservation de la tradition scénique sur la scène lyrique en France au XIXe siècle: les livrets de mise en scène er la Bibliothèque de l?association de la Régie Théâtrale". Revue de Musicologie IXIV (1978), págs. 253-267 e IDEM: Cent ans de mise en scène Jyrique en France (env. 1830-1930). Stuyvesant, New York: Pendragon Press, 1986.

4: POUGIN, A.: Giuseppe Verdi: vita aneddotica, di... con note ed aggiunte di Folchetto, illustrazioni di Achille Formis. Milano: Regio Stabilimento Musicale Ricordi, 1881, págs. 66-68
} 
que teóricamente abandona las reutilizaciones desde la década de 1830 , se puede seguir el rastro de tal práctica durante la segunda mitad de siglo; de manera que para el estreno absoluto de Les vêpres siciliennes se decoró el Acto I "avec le rideau réformé de l'acte II de La Fronde; le chateau de l'acte I du Prophète auquel on ajouterà un escalier et le palais de l'acte I de la Corbeille d'oranges" y en la première de la versión francesa de El Trovador (1875) se aprovecharon materiales de La jollie fille de Gand, La Fronde, La Vestale, Sainte-Claire y La Nonne Sanglante ${ }^{42}$. A pesar de ello -o quizá a causa de ello- las disposizione sceniche de origen francés serán adoptadas por Verdi ${ }^{43} \mathrm{e}$ introducidas en Italia como instrumento eficaz para preservar indemne la dimensión escénica de su pensamiento dramático, lo que Gilles de Van llamó "la vision dramaturgique de Verdi"44.

\section{ICONOGRAFIA TEATRAL: EL IMAGINARIO ESCÉNICO Y SU TRADUCCIÓN GRÁFICA.}

Hacia la década de los años ' 40 del siglo XIX el romanticismo ha impuesto sus criterios en la creación artística internacional y la escenografía no resulta un campo al margen. Durante las primeras décadas del ochocientos la pujanza del neoclasicismo prolonga en cierta medida la estética fraguada a fines del XVIII y sus aspiraciones de racionalizar la ilusión escénica ${ }^{45}$. El rechazo por la hipertrofia estereométrica del barroco y la ligereza decorativista rococó indujo a la adopción de

\footnotetext{
${ }^{42}$ WILD, N.: Décors et costumes du XIXe siècle. Paris: Bibliothèque Nationale, 1987 (1),
págs. 268-69.

${ }^{43}$ La primera de las disposizioni sceniche de una ópera de Verdi publicadas en Italia fue la correspondiente a Giovanna de Guzman, versión censurada de Les Vêpres Siciliennes, traducida del livret de mise en scène parisina de 1855 (Milano: Ricordi, 1856). Para más información sobre este argumento véase ROSEN, D.: "La mess'in scena delle opere di Verdi. Introduzione aile 'disposizioni sceniche' Ricordi". En La drammaturgia musicale (L. Bianconi (ed.). Polifonie. Musica e Spettacolo nella Storia. Bologna: Il Mulino, 1986), págs. 209-222.

${ }^{44}$ Cfr.: DE VAN, G.: Verdi. Un thêatre en musique. Paris: Fayard, 1992.

${ }^{55}$ El Ochocientos se inicia, a nivel plástico, de forma compleja. El Neoclasicismo pervive en los inicios del siglo XIX como doctrina incontrastada, conviviendo después con el Romanticismo y derivando hacia los estilos históricos y el eclecticismo. En un principio el Neoclásico es un arte juvenil, revolucionario, pero pronto se estanca al convertirse en dogma académico y pasar a ser el arte utilizado por el poder (máxima representación de la solidez y equilibrio del poder político), de ahí que el romanticismo irrumpa como una respuesta contraria, aunque la división tajante entre lo neoclásico y lo romántico no parece ser tal, al menos en el campo teórico, a pesar de que constituyera en la época una de las batallas campales del mundo estético, fuente se viene encomistades profundas. También en la esfera estrictamente musical se viene considerando un error establecer un período clásico opuesto a un posterior período romántico (Cfr.: PLATINGA, L.: La música de la época romántica. Madrid: Akal, 1987), pues muchos estilemas supuestamente románticos se localizan ya en el clasicismo y viceversa, llegando a decir Friedrich Blume que "el clasicismo y el romanticismo forman una unidad en la historia de la música como dos aspectos de un mismo fenómeno musical, del mismo modo que constituyen dos aspectos distintos de un único período" BLUME, F: Classic \& Romantic Music. A comprehensive Survey. New York: W. W. Norton, 1970, págs. 3-7.
} 
otras fórmulas convencionales, en las que el estilo histórico se centró en la antigüedad (un clasicismo grecolatino al cual el teatro fue especialmente sensible a través de las propuestas de los libretos) y en el respeto por la exactitud estilistica en la reproducción de las arquitecturas, asi como en una mayor fidelidad a la naturaleza y el paisaje. Sobre este substrato heredado, obviamente actualizado y condicionado por las exigencias prácticas de los recursos empleados y por las premisas estéticas de la sociedad a la que se dirige, se va construyendo el repertorio figurativo que animará el ejercicio espectacular del ochocientos con la adopción de nuevos yacimientos temáticos que explotarán, al calor de las crecientes demandas de verosimilitud histórica, etnográfica, etc. imágenes escénicas diversas. Muy pronto se observa la introducción floreciente de medievalismos y orientalismos de variada índole en correspondencia con el avance en la exaltación de un historicismo evocador, impregnado de emotividad y caracterizado por medio de una factura plástica tendente a la valoración sentimental de los ambientes, las calidades atmosféricas y la singularización pintoresquista.

La pintura teatral del XIX es fiduciaria de los recursos convencionales de representación espacial previamente desarrollados. Para los escenógrafos de to que se ha considerado primer romanticismo lírico italiano (categoria difusa y convencional que distingue la obra de maestros anteriores a $1850 \mathrm{y}$, según ciertos críticos, particolarmente di Verdi ${ }^{36}$ ) las premisas formales del idealismo neoclásico todavia siguen vigentes a través de la observancia de las reglas de la proyección perspectiva, tal y como lo demuestra su reglamentación en el tratado de Lorenzo Sacchetti Quanto sia facile l'inventare decorazioni teatrali. Guida elementare (Praga: M. J. Landau, 1830) que, junto con el apéndice Osservazioni dello stesso autore per la prospettiva prattica... (Viena: 1834) prolonga las condiciones proyectuales del Setecientos tardío en el proceder decimonónico, lo que demuestra la relevancia de las formulaciones clasicistas ${ }^{47}$. Sin embargo su preponderancia se verá 'contaminada' progresivamente en favor de recursos intrínsecamente pictóricos conducentes a nuevas evidencias plásticas. En efecto, aunque no se anule concluyentemente la solidez de la plantación y su congruencia espacial (signo peculiar de continuidad gráfica particularmente en la escena italiana), en adelante la perspectiva no será ya el elemento substancial, cediendo su primacia en interés de nuevas conquistas cromáticas, de tal manera que el tránsito hacia la plasmación de la mutabilidad

46 VIGOLO, G.: Mille e una sera all'opera e al concerto. Firenze: Sansoni, 1971, pág. 290. Este autor considera que "Le influenze di Schiller, di Victor Hugo e il grande culto a Shakespeare bastano a documentare i caratteri di questo primo romanticismo musicale italiano", Idem.

${ }^{47}$ Existen otros textos consagrados a la perspectiva que ven la luz en la Italia de la primera mitad del XIX, constando entre los más célebres, además de los mencionados:. TACCANI, F: Della prospettiva e sua applicazione alle scene teatrali. Milano: Giusti, 1825. FONTANA, G.: La prospettiva dimostrata con regole pratiche. Roma: s./e.1845. COCCHI, F: Lezioni di Prospettiva pratica e regole abbreviatrici per disegnare le scene seguite da un facile metodo per la prospettica collocazione delle figure ne' quadri di storia. Bologna: s/e., 1851 
fenoménica de la naturaleza a través del uso privilegiado del color como elemento expresivo generará un cierto debate teórico. Asi lo demuestran las críticas de Paolo Landriani quien, en 1830, denuncia el cambio que se está produciendo en la nueva generación de escenógrafos, evidencia de la dilución de la perspectiva racional a favor de la perspectiva aèrea: (...) tutta la prospettiva moderna de' pittori decoratori esser ridotta alla sola che chiamasi aerea portata sino al grado nebbioso perché tutto si vuole che s'innalzi alla leggerezza delle nubi ne' luoghi più elevati che nei più bassi, quali per far sapere che il pittore conosca l'arte di sapere alzare senza prospettiva alcuna ${ }^{48}$.

Afecta a las imágenes nocturnas y a los violentos contrastes entre luces y sombras, la escenografia decimonónica parece buscar su personalidad "en el sentimiento con que se concibe el cuadro, en la riqueza y variedad del color, y en el aliento romántico exigido tanto por los textos literarios o musicales como por el público"49. Ello enlaza con la ya apuntada vía según la cual el escenario se concibe como una caja óptica donde se inserta la figuración pictórico-perspectiva respaldada por un creciente cromatismo y por una utilización contrastada y sugerente de los efectos lumínicos, explotando los recursos del claroscuro para obtener efectos de vibración, profundidad y dinamismo, haciendo resaltar masas y volúmenes al tiempo que manifiestan el carácter y significado del episodio incidiendo en la creación de ambientes psicológicos individualizados. Alle conquiste filologiche $e$ alla crescente importanza che va assumendo il testo -afirma Franco Mancini- si affianca la potenza evocatrice cui perviene la scena mediante limpiego del colore sfruttato per la sua possibilità emotiva e la sua carica drammatica ${ }^{\text {jo }}$. La utilización del cromatismo pictórico se asimila, asi, al empleo musical de determinado color -tinta musicale apunta Verdi en una carta de 20 de agosto de $1850^{31}$ - por motivos de situación o de atmósfera, de tal manera que la imagen escénica resultante adquiria el valor subjetivo y evocativo-sentimental en sintonia con lintreccio del libretto e la concezione drammatica della musica, che tanto a cuore stava ai romantici, a Verdi in particolare ${ }^{52}$. (FiG.1)

48 LANDRIANI, P.. Osservazioni dell'Architetto e Pittore Scenico... Ob. cit., pág. 369.

49 NAVASCUÉS PALACIOS, P: "Las máquinas teatrales: arquitectura y escenografía". En Arquitectura teatral en España. (Catálogo de la exposición de la Dirección General de so

${ }^{50}$ MANCINI, F:. "Scenografia romantica, 1". Critica d'Arte XV-96 (1968), págs. 45-60, 47.

Cit. por PIGOZZI, M.: "Prampolini scenografo verdiano". En La realizzazione... Ob. cit., págs. 109-126, 113

52 PIGOZZI, M.: "Alessandro Prampolini scenografo" En Giovanni Fontanesi, Alessandro Prampolini, Alfonso Beccaluva. Paesaggisti reggiani dell'Ottocento (E. Monducci (ed.). Catalogo

della mostra. Reggio Emilia: Sale del ridotto del Teatro Municipale, 28 aprile-20 maggio 1984.
Reggio Emilia: Tipografia Emiliana, 1984), págs. 46-90, esp. 59-60. 


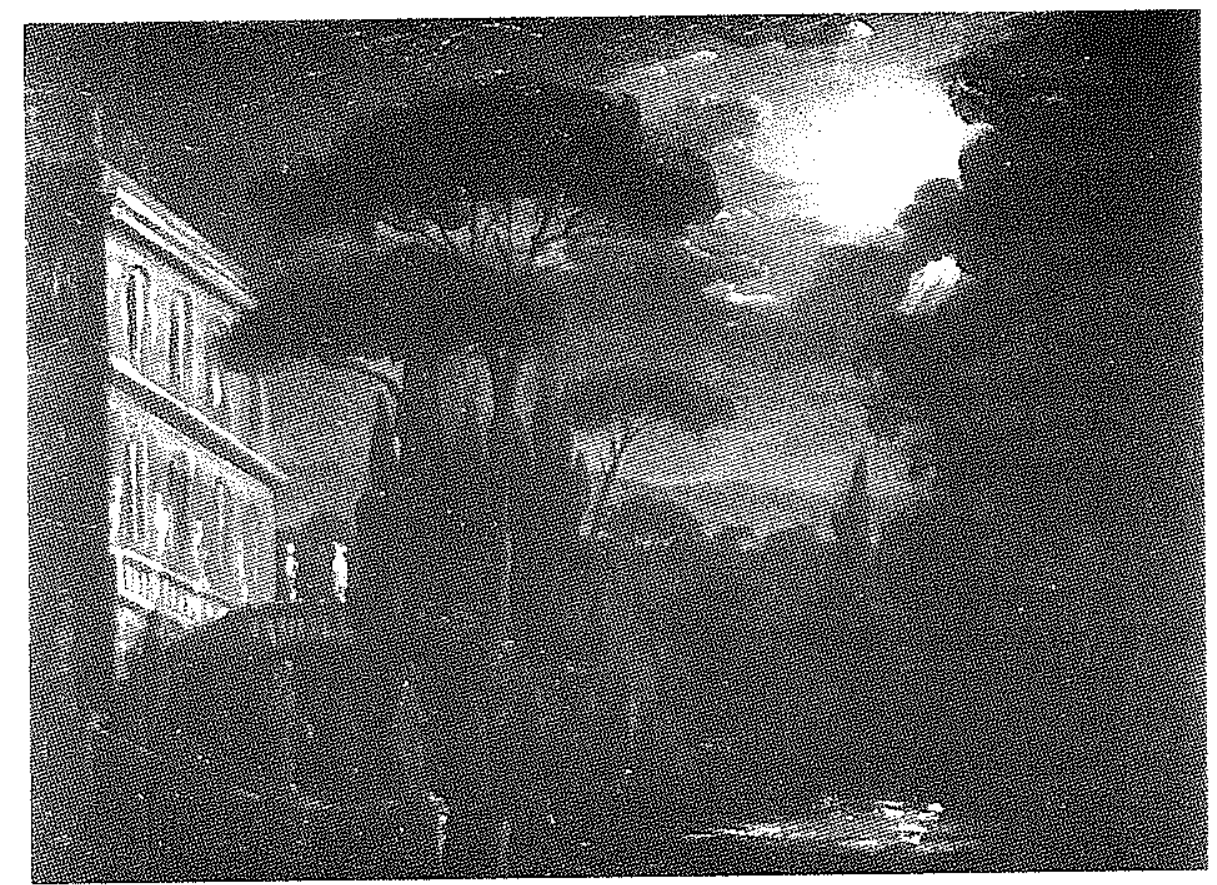

1. Verdi: Il Trovatore Alessandro Prampolini: 'Jardines del Palacio de la Aljaferia' (Acto I, c.2; Roma. Teatro Apollo. 19-I-1853: prima assoluta). Roma, Colección privada

Parece oportuno reseñar, en este punto, el primer contacto entre el compositor y quien sería uno de sus más asíduos escenógrafos, Giuseppe Bertoja, con motivo del estreno en el Teatro Regio de Turín de Oberto durante el carnaval de 1840. El empleo del color a manos de Bertoja en los decorados de esta ópera verdiana ("siamo stati invitati a vedere due montagne verdi, una città gialla e un castello color rosa" se leía en la critica del Messagiere Torinese ${ }^{53}$ ) demuestra un evidente desembarazo de formalismos doctrinales en favor de un código cromático sugestivo, medio de comunicación efusiva más que de esmerada ilustración, en perfecta sintonia con todo lo anteriormente expuesto. No hacen falta testimonios explicitos de la aquiescencia de Verdi respecto de tal realización si tenemos en cuenta que a partir de este momento Bertoja colaboraria con el maestro en numerosos proyectos, entre los que se encuentran seis estrenos absolutos, además de un gran número de

\footnotetext{
${ }^{53}$ Il Messagiere Torinese (18-1-1840). Cit. por DE CARIA, F: "Scheda n V19". En Il Teatro Regio di Torino, 1740-1990. Larcano incanto (A. Basso (com.). Catalogo della mostra. Torino: Teatro Regio, 16 maggio-29 settembre 1991. Milano: Electa, 1991), pág. 473.
} 


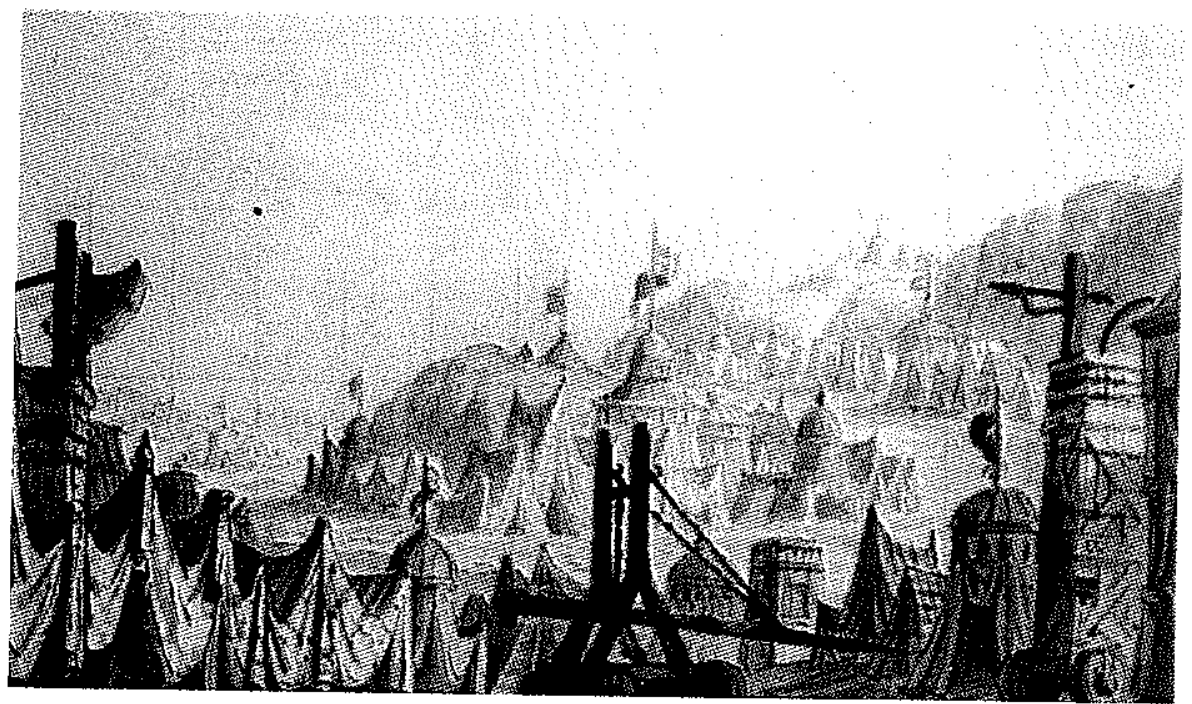

2. Verdi: I Lombardi alla prima crociata. Giuseppe Bertoja: 'Campamento lombardo' (Acto IV, c.2. Turin. Teatro Regio. Temporada 1843-44). Venezia, Civico Museo Correr.

representaciones y reposiciones en diversos teatros ${ }^{54}$. Por otro lado no se han conservado -o todavia no se han identificado- testimonios gráficos de los primeros estrenos scaligeros de Oberto, Un giorno di regno, Nabucco o / Lombardi, habiendo de recurrirse a los diseños de Bertoja como las fuentes más antiguas de la naciente escenografia verdiana $a^{55}$. (FiG.2)

Pero a pesar de la importancia conferida a las posibilidades del juego cromático como material revelador del contenido emocional del cuadro y la inclinación de la pintura teatral por implicar de manera sinérgica imagen escénica y acción dramática en un "tour de force" destinado a conmocionar al espectador, durante todo ef ochocientos y hasta la aparición de los primeras divergencias de la vanguardia finisecular, la función más reconocida y valorada en los decorados era la función representativa. El cometido esencial de la producción escenográfica radicaba en representar el lugar de la acción dramática, incidiéndose en el papel figurativo del

${ }^{54}$ Ernani, Attila, Rigoletto, La Traviata y Simon Boccanegra para La Fenice de Venecia, y Stiffelio para el Teatro Grande de Trieste. Cfr.: MURARO, M. T.: "Le scenografie delle cinque 'prime assolute' di Verdi alla Fenice di Venezia". En Atti del I Congresso Internazionale di Studi Verdiani (Parma: Istituto Nazionale di Studi Verdiani, 1969), págs. 328-334.

VIALE FERRERO, M.: "Luogo teatrale e spazio scenico". En La spettacolarità (Vol. V de Storia dell'opera italiana, Parte II 'I Sistemi'. L. Bianconi y G. Pestelli (eds.). Torino: Società Italiana di Musicologia, Edizioni di Torino, 1988), págs. 1-122, 98. 
material escénico (reproducción topográfica e histórica del espacio argumental) como su razón de ser, de tal manera que el paso del descriptivismo prolijo a un realismo más exhaustivo puede interpretarse en cierta medida como una evolución natural, pese a que la frialdad "fotográfica" también será criticada, como veremos más adelante en relación con el propio Verdi.

Será a partir de los primeros decenios del Ochocientos cuando los escenarios extiendan sus límites a todas las épocas y todas las civilizaciones, incluyendo entre sus intereses el gusto por el retrato ambiental y la persuasión psicológica. El romanticismo desliza el proyecto neoclásico de la verosimilitud desde la doctrinaria objetividad racional y la fidelidad histórica al plano de la realidad subjetiva y la interpretación personal, confirmándose desde entonces un historicismo escénico cuya definición programática podria compendiarse como la manifestación visual de eventos históricos o de narraciones literarias, sucesos auténticos o ficticios, en una linea que continuará a través del eclecticismo hasta bien entrado el siglo $X X^{56}$. Esta vivida revelación material al observador de un mundo supuesto ricostruisce volta per volta atmosfere fedeli al testo interpretato, per un pubblico che dal teatro attende non più meraviglie cosmogoniche, bensi emozioni riconducibili dalla sfera colletiva a quella privata?

Puede apreciarse una indiscutible tendencia hacia la evasión temática en el espacio y en el tiempo, sustentada argumentalmente por las tramas de los libretos y visualmente acreditada por el imaginario escénico. Fantasía y exotismo se unen en la voluntad escapista hacia la ensoñación de mundos pretéritos, transfigurados, insólitos, fabulosos o extraños con frecuentes incursiones de lo ultraterreno y el concurso "bizarre" de lo escatológico ${ }^{56}$. El universo plural que reclama el romanticismo se orienta persistentemente hacia el medievo y la época moderna renovadas veleidades goticistas ${ }^{59}$ que fluctúan desde el primitivismo estilístico de los

\footnotetext{
5. "La experiencia contemporánea del arte escénico está marcada por la fijación cultural de ciertas formas del teatro burgués de mediados del XIX que se resisten a dejar escapar de sí el concepto mismo de teatro". SÁNCHEZ, J. A.: Dramaturgias de la imagen. Cuenca: Eds. de la Universidad de Castilla-La Mancha, 1999, pág. 13

57 TAFURI, M.: Teatri e Scenografie. Milano: Serv. Publ. Touring Club Italiano, 1976, pág. 34.

${ }^{58}$ La galería romántica, en este sentido, resulta inagotable. Centrándonos en el compositor que nos atañe cabría recordar algunas escenas significativas de títulos verdianos, como la visión de Giselda y el coro de espíritus celestes de I Lombardi (AIV, 1) o la de Jacopo en I Due Foscari (AII, 1); los coros de ángeles y de demonios de Giovanna d'Arco (Prólogo 2; AI, 2; AIII, finale); las brujas, las apariciones de los espectros de los ocho reyes y el fantasma de Banquo en

Macbeth (AI, 1; AII, 3; AIII); el racconto de Ferrando en II Tovatore (AI, 1); las predicciones de la hechicera en Un Ballo in maschera (Al, 2); o las célebres participaciones de la voz del cielo y de la sombra de Carlos V en Don Carlos (A2 -1867/3 -1884, 2; A5 -1867/4 -1884, finale).

59 Elementos góticos, como estilo bárbaro e incluso exótico, ya habían aparecido en la decoración teatral deI XVIII.
} 
modos "troubadour" sentimiento de herencia cultural, alimentado además por las modas de la novela histórica, poemas dramáticos, leyendas y relatos de terror, la reivindicación de figuras como Shakespeare o la obra de Schiller, Walter Scott, Hugo, etc ${ }^{61}$ ), huyéndose de un contacto excesivamente intimo con la realidad, sobre todo inmediata. Así la "libretistica" refleja aquel movimiento de aproximación y de fuga de la realidad que se daba en la poesía del siglo ${ }^{62}$.

Tomando como evidencia el propio catálogo verdiano, resulta que únicamente /I Corsaro (ambientado en el Egeo), Stiffelio (que transcurre en Austria, más tarde convertido en el feudal Aroldo) y La traviata (antes y después de ser diferida al XVIII) responden a tramas contemporáneas. El resto de los títulos se adentran en los dominios del pasado, oscilando entre la Edad Moderna occidental de los siglos XVII ${ }^{63}$ y XVIII ${ }^{64}$, con una rotunda preponderancia de la Alta y Baja Edad Media europea ${ }^{65}$ y la comparecencia demostrativa de un exotismo que se desplaza desde la conquista de América (Alzira, Lima y Perú) hasta la antigüedad previa a nuestra era (Nabucco, Jerusalén y Babilonia -587 a.C-; o Aida, Menfis y Tebas en tiempos faraónicos), con mixtificaciones en / Lombardi, Jérusalem u Otello si tenemos en cuenta, como se ha (i) Cfr.: PUPL, F: Le Style troubadour ou la Nostalgie du bon vieux temps. Nancy: Presses
Universitaires de Nancy, 1985.

i1 El teatro lírico decimonónico demuestra una proporción altísima de adaptaciones, traducciones o arreglos de textos preexistentes, estrategia que avalaba su operatividad en diversos ordenes: por un lado las funciones del código estructural asimilado habían sido ya difundidas previamente en círulosas de antemano; por otro lado solía tratarse de obras que, notoriedad popular, en circulos culturalmente más o menos restringidos, gozaban de cierta directa expectativa y predisponía al gran público a conocerlos directamente (en un proceso similar a las actuales adaptaciones cinematográficas de novelas u melodramma. Ob. PORTINARI, F. "Pari siamo. Sulla struttura del libretto romantico". En 1$]$ melodramma... Ob. cit.), págs. 545-566, 546-47. La producción de Verdi confirma estos alla prima crociata) hastre desde poemas dramáticos de Byron (ll Corsaro) o Grossi (I Lombardi Rigoletto), el mismo hasta - y fundamentalmente- piezas teatrales de Victor Hugo (Emani, Millet, Don Carlos yaron (I Due Foscan), Schiller (Giovanna d'Arco, I Masnadieri, Luisa (Macbeth Cartos y parcialmente La forza del Destino), Voltaire (Alzira), Shakespeare traviata). Precisamente a García Gutiérrez (II Trovatore, Simon Boccanegra) o Dumas (La integra la obra verdian a casusa de tales referentes literarios un sector de la historiografía :2 BALDACCl,

${ }_{63}$ Luisa Miller, Tirol; Un ballo in

65 Un giorno di regno, Bretaña; I Masnadieri, Alemania; La forza del destino, España e Italia. Jerusalen; Ernani San Bonifacio, Bassano; I Lombardi alla prima crociata, Milán, Antioquía y os, Aix-la-Chapelle y Zaragoza; I due Foscari, Venecia; Giovanna Macbeth Rigoletto, Mantu, Jerusalem, Toulouse y Palestina; La battaglia di Legnano, Milán y Como; Boccanegra Géna; II trovatore, Vizcaya y Aragón; Les vêpres siciliennes, Palermo; Simon Otello, Chipre; y Falstaff, Inglaterra. 
afirmado repetidamente, que el "orientalismo de salón" decimonónico comenzaba en Grecia y conocía en Tierra Santa un fecundo manantial de inspiración ${ }^{66}$.

Este itinerario resulta aún más significativo al tener en cuenta que si ignora generalmente che Verdi è in massima l'autore di tutti i libretti da lui messi in musica. Egli non solo sceglie i sogetti delle sue opere, ma forma anche la trama dei librett ${ }^{57}$. La certeza de tal aseveración es relativa, pues las eventualidades fueron múltiples y variadas en lo que atañe a la elección y exégesis del material poético utilizado por verdi en cada caso. De cualquier modo, lo que si parece incuestionable es el celo con que el compositor tendia a intervenir sobre los textos que ponia en música como matriz dramatúrgica base, asi como que la galeria escénica por él recorrida no es sino el reflejo de los loci classici teatrales de su tiempo.

El siglo XIX extendió a todas las épocas y lugares el concepto de verosimilitud, reivindicando a un tiempo la necesidad de la "naturaleza" o perfecta ilusión y de la individualización o "color local", ese conjunto de rasgos peculiares de una región o localidad en cuanto pueden excitar la imaginación por su carácter peculiar y pintoresc $\mathrm{O}^{68}$, además del "carácter de época". En el respeto a estos principios residía el fundamento basilar de la puesta en escena historicista, de cuya legitimidad Verdi era un convencido: tutte le epoche hanno, è risaputo, i loro caratteri particolar $r^{9}$. La consecución de esta aparente autenticidad dramática y representativa discurrió a través de la búsqueda de una inteligibilidad cómoda y una contextualización (histórica y geográfica) inmediata de las escenas presentadas por parte del espectador.

Las referencias icónicas barajadas por los escenógrafos en la recreación de tan vasta y heterogénea profusión de emplazamientos y circunstancias procedieron de diversas fuentes. Tambièn en este orden la substancia literaria es importante, desde la historiografia cientifica ("Historias naturales", etc) hasta las descripciones poéticas y noveladas, pasando por la bibliografía periegética, que en el XIX puede participar de ambas categorias. Ciertamente los relatos de viajeros detentan una solvencia

${ }^{6}$ THORNTON, L.: Les orientalistes: peintres voyageurs, 1828-1908. Paris: ACR Edition, 1983, pág. 13. Cfr. asimismo: LATOUR, M., LEHALLE, E. y BOUILLE, M.-C.: L'orient en question: 1825-1875. De Missolonghi à Suez ou l'Orientalisme de Delacroix à Flaubert. Marseille: Musée Cantini, 1975. JULLIAN, P.: Les orientalistes. La vision de l'Orient par les peintres européens au XIXe siècle. Fribourg: Office du Livre, 1977. VERRIER, M.: Les peintres orientalistes. Paris: Flammarion, 1979. Voyage en musique. Cent ans dexotisme: décors et costumes dans le spectacle lyrique en France (Catalogue de l'exposition. Boulogne-Billancourt: Centre Culturel de Boulogne-Billancourt et Bibliothèque Marmottan, 4 mai-13 julliet 1990). Paris: Lithographie Parisienne, 1990.

67 POUGIN, A.: Giuseppe Verdi: vita aneddotica... Ob. cit., pág. 68.

${ }^{6}$ Diccionario de la lengua española. Madrid: RAE, 1992, ad vocem.

69 Carta de Verdi a F. Arpino (III-1858). En En OBERDOFER, A. (ed.): Giuseppe Verdi. Autobiografia... Ob. cit., pág. 303. 
decisiva en la propagación de un imaginario, en ocasiones imposible, a partir de las impresiones reflejadas de territorios remotos que oscilan entre la seducción de lo pintoresco y la fabulación onírica: (...) les plus grands metteurs en scène et propagandistes de ces espectacles qui feront leur entrée à l'opéra ne furent pas les poètes, mais les voyageurs. Ce sont eux qui inaugurèrent cette grande poésie si typiquement romantique, où la realité matérielle était exaltée dans les reflets du mythe, à une époque fascinée par le tragique de lantique et le primitif'.

Una de las manifestaciones más presentes, permanentes y opulentas de este fenómeno se centra en la egiptomania, que condimentó muy diferentes géneros de la expresión artistica occidental y que en el caso del teatro llegó a convertirse frecuentemente en un vehículo cultural de la actualidad arqueológica, utilizando como fuentes tas publicaciones más recientes y mejor documentadas para reinterpretarlas según diversos criterios $^{71}$. En lo concerniente a la escenografia decimonónica la necesidad de documentación -trámite ineludible en la consecución del realismo- se vio satisfecha por las numerosas obras que sobre ef tema fueron editando autores desde Champollion", pasando por los diversos trabajos del "pintor de arqueologías" David Roberts ${ }^{33}$ (quien por cierto comenzó su carrera profesional como escenógrafo) hasta Lepsius o Prisse d'Avennes" que tanto ascendiente tuvieron en el ideario escénico concebido por Auguste Mariette para Aida ${ }^{75}$ sin

\footnotetext{
MACCHIA, G.: Le prince de Palagonia. Monstres, songes et métamorphoses d'un personnage.
Paris: Quai Voltaire, 1987, pág. 17 .

"É Cfr.: HUMBERT, J.-M.: L'Égyptomanie dans l'Art Occidental. Paris: ACR Edition, 1989; IDEM. "Égyptomanie et spectacles scéniques du XVIIIe siècle à nos jours: les raisons de fa fréquente dichotomie entre les progrès de l'archéologie et l'interpretation qu'en proposent les artistes". En Thêâtre et spectacles hier et aujord'hui. Époque moderne et contemporaine. Paris: Éditions du comité des travaux historiques et scientifiques, 199, págs. 485-495.

72 CHAMPOLLION, J. F: L'Égypte sous les Pharaons, ou recherches sur la géographic, la
religion, la langue, les écritures et l'hiscire dét religion, la langue, les écritures et l'histoire de l'Égypte.... Paris: Impr. de J.-H. Peyronard, et de la Nubie, par... Paris: Impr. Firmin Didot, 1845 . "s SOBREGRAU, C.: "Davis Roberts. Un p

págs. 20-31. ROBERTS, D.: Wievs in pintor de arqueologías". Album Letras-Artes 14 (1985): from drawings made on the spot in the Holy Land, Syria, Idumea, Arabia, Egypt \& Nubia; George Croly. Egypt \& Nubis with historical descriptions by illiastiptions by the Revd. Louis Haghe. 5 vols. London: F. G. Moon, páos. 1842-49. Wy William Brockedon. Litographed by ${ }^{4} 4$.

${ }^{74}$ LEPSIUS, R.: Königsburg der alten Ägypter, von C. Richard Lepsius. Berlin: Bessersche Buchhandlung (W. Hertz), 1858. IDEM. Letters from Egypt, Ethiopia and the Peninsula of Sinai. zeichnungen der von Seiner Majestaet dem koenige vonpten und Aethiopien nach den Nicolai, 1849-56. domination française. Paris, Firmin Didot Egyte depuis la conquête des Arabes jusqu'à la Bertrand, 1858.

Pars, Firmin Didot, 1848. IDEM: Historire de I'Art Egyptien... Paris, A.

${ }^{75}$ Cfr: "Genesi dell'Aida con con documentazione inedita a cura di S. Abdoun. Ouaderni dell'Istituto di Studi Verdiani 3 (1971); HUMBERT, J.-M.: "Aïda de l'archéologie à l'égyptomanie". En Verdi. Aida. LAvant Scène Opéra $4\left(2001^{3}\right): i$, págs. 8-15. El texto italiano de
} 


\section{Verdi: Aida. Philippe Chaperon: 'Columnata que se abre al exterior' (Acto I, c.l. El Cairo. Teatro de la Opera. 24-XII-1871: prima assoluta). Paris, Bibliotheque Musée de lopéra.}

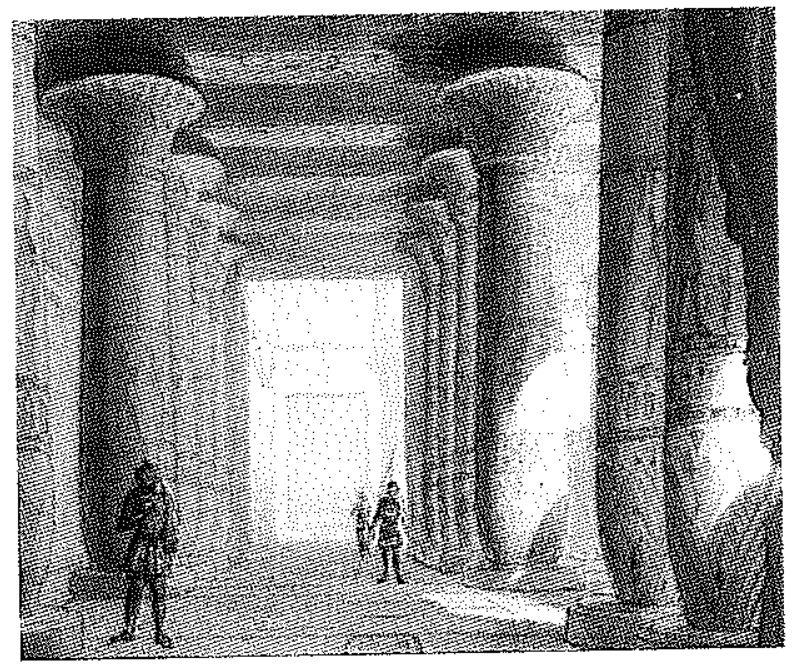

olvidarnos de la enorme trascendencia de la Description de l'Égypte (1809-1822) cuyo influjo puede advertirse incluso en 1871 cuando uno de los bocetos de Philippe Chaperon para el estreno mundial de esta ópera en el Teatro de la Ópera de El Cairo (Al, c1: colonnato che si apre sullesterno) se inspira directamente en un grabado del templo de Amón-Ra en Karnak incluido en uno de los volúmenes de esta monumental obra $^{77}$. (F/G. 3)

Incluso para el estreno italiano de esta ópera traducciones de ejemplares franceses como el Voyage de Denon, publicaciones italianas como la obra de l. Rosellini $y$, por supuesto, parte de la producción del egiptólogo Mariette ${ }^{78}$ han sido

Mariette, junto con el original francés, pueden encontrarse en Humbert, J.-M. "À propos de l'égyptomanie dans l'oeuvre de Verdi: attribution à Auguste Mariette d'un scénario anonyme de l'opéra Aida". Revue de Musicologie LXII (1976), págs. 229-256.

${ }_{76}$ Description de l'Egypte ou Recueil des observations et des recherches qui ont été faites en Egypte pendant l'expédition de l'Armée française publié sous ler ordres de Napoléon Bonaparte. 5 vols. Paris: Impr. Impériale [puis Impr. Royale] 1809-1822 (reed. anast.: Sydney H. Aufrère pref. Paris: Bibliothèque de l'Image, 1993). MEHEDIN, L.: Description de l'Égypte, commencée sous les auspices de Napoléon Ier, continuée par ordre de Napoléon III... par Léon Méhédin. Paris: Impr. de Firmin Didot frères, fils et Cie., 1859.

$"$ Vid. FONTAINE, G. y KERHOAS, M.-J. (coms.): "scheda n. 181". En Sogno e Delirio. Scenografie d'opera dalla Bibliothèque Nationale de France-Bibliothèque-Musée de l'Opéra de Paris (Catalogo della mostra. Roma: Accademia di Francia a Roma, Villa Medici, 22 ottobre-7 gennaio 1998. Milano: Electa, 1997), págs. 88.

${ }_{78}$ DENON, D.: Viaggio nel basso ed alto ed alto Egitto illustrato dietro alle tracce e ai disegni del Sig. Denon. Firenze: presso Giuseppe Tofani, 1808 (ed. orig.: Voyage dans la Basse et la Haute-Égypte pendant les campagnes du général Bonaparte, pas... Paris: Impr. De Migneret, an X [1802]); ROSELLINI, I.: I monumento dell'Egitto e della Nubia disegnati dalla spedizione scientifico-letteraria toscana in Egitto distribuiti in ordine di materia interpretati ed illustrati. 
identificadas como fuentes consultadas por Girolamo Magnani para la elaboración de los decorados de la Aida scaligera de $1872^{79}$.

Todo este substrato literario favoreció una apariencia en numerosas ocasiones poética, "libresca", de las decoraciones, en la que descripción y evocación se compensaban en el resultado plástico: "los temas e incluso la voluntad de deformación idealista emparejan a escritores y pintores románticos, cuya única diferencia viene condicionada por las exigencias de los medios específicos de los que se sirven" 80 . A ello debemos sumar la participación del libretista, cuya potestad, a través de un aparato didascálico puntilloso y preciso (caso de el colaborador de Verdi en Un giorno di regno Felice Romani ${ }^{81}$ ), se hacia notar de la misma manera que a través de su intervención directa en la puesta en escena de las óperas, una costumbre que no empezó a declinar hasta el último cuarto del siglo $X I X^{82}$. No en vano, durante el siglo XIX, los pintores se embebieron de literatura y los escritores trataron de emular a los pintores, según ha señalado Mario Praz ${ }^{33}$.

Por otra parte el Ochocientos se caracteriza por una intensisima circulación de imágenes a través de diversos soportes que facilitaban su divulgación y el acceso de informaciones a sectores de población cada vez más amplios: estampas y láminas, impresiones y grabados en diversas técnicas... sin olvidarnos de la prensa ilustrada, competente medio de propalación de un muestrario gráfico que respondia a los gustos e inquietudes de la sociedad, satisfaciendo sus demandas de información y consumo, y que operaba como un canal de transmisión del que ya era consciente la crítica contemporánea: un torrente di litografie, di viaggi, di giornali pittoreschi, nelle sale, nei caffé, nelle strade, porta a cognizione di tutti i viventi ciò che prima era olla di pochi escribe Cattaneo en 1839 con relación a la pintura de escena ${ }^{a 4}$.

Pisa: presso Noccolò Capurro, 1832; MARIETTE, A.: Dendérah. Description générale du grand temple de cette ville. Paris: Franck, 1870-71.

${ }^{79}$ Cfr.: OLIVERO, G.: "'Aida' tra egittologia ed egittomania". Studi Verdiani 10 (1994-95): 118

80 CALVO SERRALlER, F: La imagen romántica de España. Arte y arquitectura del siglo XIX Madrid: Alianza Editorial, 1995, pág. 22.

${ }^{81}$ Vid.: RINALDI, M.: Felice Romani: dal melodramma classico al melodramma romantico. Roma: De Sanctis, 1965. SOMMARIVA, A. (ed.). Felice Romani: melodrammi, poesie, documenti. Firenze: L. S. Olschki, 1996. ROCCATAGLIATt, A.: Felice Romani librettista. Lucca:

"2 Cfr.: ENGELHARDT, M.: "Verdi regista di 'Aida". En La realizzazione scenica... Ob. cit., págs.
$58-71,58$ n3 $58-71,58 \mathrm{n} 3$

Madrid: Taurus PRAmosyne. El paralelismo entre la literatura y las artes visuales. Ensayistas 148. Madrid: Taurus ediciones, 1981, pág. 178.

${ }^{34}$ CATTANEO, C.: "Del arte prospettica e principalmente della pittura scenica in Lombardia". Il Politecnico I-2 (1839). Reprod. en Anceschi, G. y Armani, G. (eds.). Scritti sulla Lombardia.
Milano: Ceschina, 1971, pág. 725. 
Paralelamente progresa la conciencia de la necesidad de mantener un recuerdo perdurable medio de reproducciones gráficas que permitieran una eficaz difusión de los logros alcanzados en las puestas en escena, o almeno i concepimenti e i disegni (...) a modello degli studiosi ed alla memoria de' poster ${ }^{85}$. No se trata ya del ejercicio barroco de la retórica del poder vinculado al sistema de competencias politicas y culturales en que se desenvolvian las cortes europeas, sino de una estrategia práctica en la tendencia a definir un prontuario de modelos ejemplares y reproducibles:

l'esistenza di un repertorio operistico determina la formazione di un repertorio scenografico; alle repliche numerose e ricorrenti di un'opera corrispondono immagini replicate: l'allestimento modello sarà quello della 'prima assoluta' e circolerà se e in quanto circolerà l'opera per la quale è stato creato. (...). II concetto della scena come essempio replicabile guiderà e dominerà il corso successivo della scenografia fino al termine dell'Ottocento ${ }^{86}$.

De esta manera, numerosos escenógrafos se entregan a generar grabados y litografias de composiciones decorativas ideales, a la reproducción de aquellas que hubieran obtenido el éxito y la alabanza del público, a la ilustración propedéutica de ejemplos con intención didáctica para futuros profesionales o a la transmisión de matrices figurativas que se pretendian canónicas por compendiar la especificidad expresiva requerida por el drama (una de las exigencias del propio Verdi) y una factura plástica de reconocida calidad ${ }^{87}$. Asimismo, la promoción y circulación de

${ }^{85}$ GIRONI, R.: Sulle decorazioni sceniche ed in spezie... Ob. cit. pág. 313.

${ }^{86}$ VALE FERRERO, M.: "L'immagine seducente. L'allestimento scenico". En Il Teatro Regio di Torino, 1740-1990. Larcano incanto (A. Basso (com.). Catalogo della mostra. Torino: Teatro Regio, 16 maggio-29 settembre 1991. Milano: Electa, 1991), págs. 441-497, 449.

${ }^{67}$ Ciñéndonos exclusivamente al caso italiano y tomando como ejemplo más llamativo la actividad desarrollada al respecto en torno a Milán al calor del Teatro alla Scala, nos encontramos durante las tres primeras décadas del siglo con numerosas ediciones (distribuidas en fascículos o en formato de álbumes litográficos -más frecuentes a partir de 1850-) que conocieron notable difusión, entre las que podríamos destacar Raccolta di secene teatrali eseguite o disegnate dei più celebri pittori scenici in Milano (Milano: 1819); Collezione di varie scene teatrali, date in Iuce da A. Basoli... Disegnate da Gaetano Sandri e da altri scolari dell'autore, e dai fratelli del medesimo Luigi, e Francesco Basoli... (Bologna, 1821); Raccolta di scene teatrali (Milano: 1820-30); Raccolta di prospettive serie, rustiche e di paesaggio (Bologna, 1820); Scelta di Sceniche Decorazioni inventate ed eseguite dall'Architetto Pittore scenico Alessandro Sanquirico per IT. R. Teatro della Scala di Milano (Milano: c. 1826); Raccolta di varie Decorazionj sceniche Inventate ed eseguite da Alessandro Sanquirico Architetto-Pittore scenico degl' Teatri di Milano (Milano: c.1827) y Nuova raccolta di scene (Milano: Ricordi, 1827); Raccolta di scene teatrali (Milano: S. Stucchi, 1828); Raccolta di prospettive serie, rustiche e di paesaggio (Venezia, 1830); Raccolta Inedita di cinquanta Scene Teatrali. Le più appaludite nei teatri italiani, disegnate ed incise da L. Ruggi (Bologna: c.1840). En el caso francés también se pueden encontrar numerosos ejemplos, entre cuyos exponentes parisinos citaremos: Décorations théâtrales (Paris: Léger-Larbouillat, 1830); Album des Théâtres (Paris: Guyot, 1837); Album de l'Opéra (Paris: Challamel, 1844); CHASLES, D: Les beautés de l'Opéra (Paris: Soulié, 1845). 


\section{Verdi: Attila. Giuseppe Bertoja: \\ 'Rio-Alto en las lagunas Adriáticas' \\ (Prólogo, c.2. Venecia. Teatro de \\ La Fenice: prima assoluta \\ 17-III-1846). Litografía, L'Italia \\ Musicale, 1847}

modelos fomentada por los propios autores o sus editores resultará una táctica frecuente y útil (ligada a la iniciativa de las disposizione sceniche) en la difusión de patrones adecuados a través de su inserción en la prensa ilustrada, las colecciones de grabados e incluso su impresión en las portadas de las partituras. Resulta ejemplar, en este sentido, la publicación por Lucca en 1847 de una reproducción litográfica de un diseño ideado por Giuseppe Bertoja para el estreno de Attila en La Fenice ${ }^{\sharp 8}$.

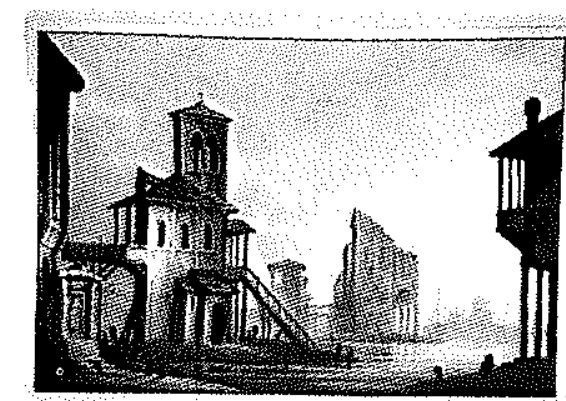

en concreto aquél que presentaba Rio-Alto en las Lagunas Adriáticas (Prólogo, c2), en el que se incluye la planimetría y que se asentaria como arquetipo en la interpretación visual de la escena para futuras representaciones. (Fis. 4)

No resulta éste un caso único, pudiendo citarse al respecto la litografia a color publicada por la Gazzetta Musicale di Milano ese mismo añog que representa una de las brujas del Macbeth veneciano, cuya pauta se repitió sustancialmente en la revisión francesa de 1865 y se mantuvo hasta la reposición de 1874 en La Scala como puede comprobarse a través de los figurines realizados por Luigi Bartezago al efecto ${ }^{90}$. Del mismo modo cabría señalar la aparición en las páginas de L'lllustration de todas las escenas de la première parisina del Don Carlos"1 que parece fueron tomadas como referencia por Carlo Ferrario para el estreno italiano en La Scala (1868) o, en sentido contrario, las creaciones de Ferrario para la prima assoluta de Otello, reproducidas abundantemente en la prensa periódica italiana, no sufrieron

\&. Ltalia Musicale I-15 (13-X-1847): 113

Gazzetta Musicale di Milano 4 (1847),

"Cfr.: JESURUM, O.: Schede n. 16-18. En "Sorgete! Ombre serenel"... Ob. cit., pág. 154.

${ }^{9}$ L'Tllustration XLIX (16-III-1867). 


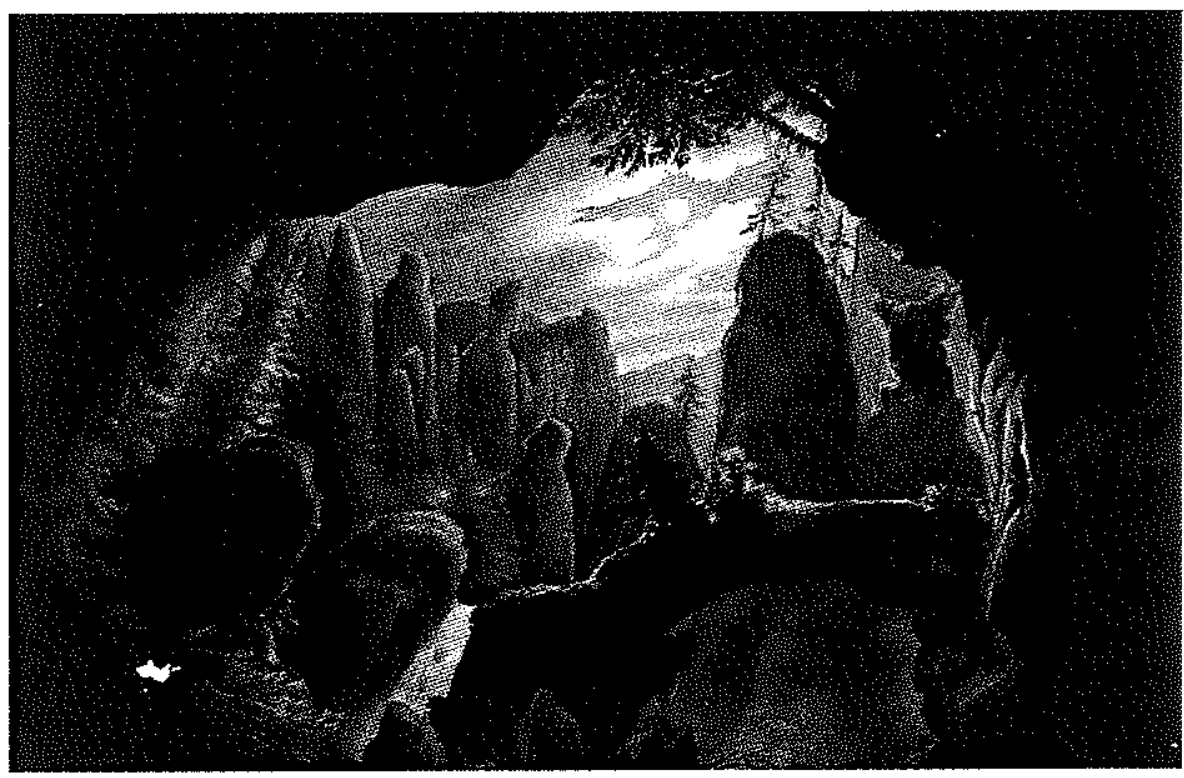

5. Verdi: La forza del destino. Andreas Leonhard Roller: 'Valle entre riscos inaccesibles' (Acto IV, c.2. San Petersburgo. Gran Teatro Imperial, 10-XI-1862: prima assoluta. San Petersburgo, Museo estatal de Teatro y Música.

modificaciones de base en su interpretación francesa, tal y como se puede comprobar de nuevo a través de las páginas de $L$ 'lllustration ${ }^{92}$,

Lógicamente, la pintura de caballete también influyó en el proceder escenográfico, pudiendo encontrarse fecundos vínculos, evidentes sobre todo en el terreno del paisajismo y en el género de historia. Con respecto a la pintura de paisaje se muestran dos tendencias principales que encontrarán elocuentes testimonios operísticos; por un lado la naturaleza pintoresca: conocida, acogedora, amiga, cercana, bucólica o idílica, tratada preferentemente en los géneros semiserio o cómico. Por otro lado la naturaleza sublime: amenazadora, agreste, inaccesible, casi mística, vehículo de las fuerzas cósmicas a través de manifestaciones telúricas como tormentas, erupciones volcánicas, incendios... un concepto de donde dimana el culto a la ruina, explicado por la recuperación de la Historia, la obra humana degradada por las fuerzas naturales que la hace encajar en el paisaje, equilibrio expresivo entre civilización y naturaleza. (FiG. 5)

92 LIllustration CIV (13-IX-1894). 
En este contexto, la proclividad al subjetivismo emotivo en la representación de ambientes sumada a la tendencia abierta por el romanticismo al decorado majestuoso y a la acción extensa $a^{93}$ encuentra en el tratamiento de la naturaleza sublime generosas resonancias líricas. Conviene recordar aqui algunos elementos de la cultura escenográfica francesa del último cuarto del XVIII vinculados al pathos efectista, espectacular y arrebatado ${ }^{94}$ cuyo éxito llevará a compositores y libretistas a abundar en tales situaciones dramáticas, estableciendo una tradición que será exportada a Italia -a través de Nápoles fundamentalmente- y explotada por su producción operística $a^{95}$ en una línea de larga continuidad durante el siglo $X I X^{96}$, con títulos de tanta repercusión como $L^{\prime}$ Ultimo giomo di Pompe $P^{97} \mathrm{o}$, de vuelta en Francia, La muette de Portici $i^{96}$. En este mismo interés por to intemperante, la fatalidad y lo sensacional, encaminado a explotar la amplia gama de la emoción, podriamos citar otros titulos célebres como las rossinianas Mosè in Egitto ${ }^{99} \mathrm{o}$ Le siège de Corinthe ${ }^{100}$

43 TATCHER GIES, D.: El Teatro en la España del siglo XIX. Londres: Cambridge University Press, 1996, pág. 206.

${ }^{94}$ Ya presentes en obras como Les Danaïdes de Antonio Salieri (tragedia lírica en cinco actos con libreto de M. F. Gand L.eblanc Roullet sobre texto de R. de' Calzabigi; estrenada en el Théâtre de l'Opéra de Paris el 26-IV-1784)

${ }_{95}$ A partir de títulos como Ecuba de N. A. Manfroce ('tragedia per musica' en tres actos con libreto de G. Schmidt, estrenada en el Teatro San Carlo de Nápoles el 13-XII-1810)

\% Ello viene a corroborar la identidad del romanticismo, al margen de su fenomenología artística, como una transvanguardia: una tensión estilístico/ideológica que se manifiesta a través de sucesivos procesos culturales -La difficoltà, olimpossibilità, di definire il fenomeno romantico nella sua unità essenziale non esclude d'altra parte la possibilità di rilevare in esso alcune 'costanti' (...), dei motivi conduttori, che sono alla base del romanticismo stesso e che continuamente affiorano, sebbene atteggiate in modo diverso, nella realtà concreta delle singole manifestazioni e delle situazioni particolari. TERENZIO, V: La Musica italiana nellOttocento. Milano: Bramante Editrice, 1976 (I): 12-, y como tal presente ya de forma embrionaria, incluso a nivel léxico, en 1650 (el adjetivo inglés romantic aparece como un neologismo que comienza a usarse hacia 1650 para indicar la "materia aventurera" de los romances (novelas de caballería) en oposición a novel. Poco tiempo después pasó a designar aquello que en los paisajes y ruinas hace referencia al ámbito de la imaginación y, por tanto, conecta con la "dimensión de lo irracional" (DE PAZ, A. La revolución romántica. Madrid: Tecnos, 1986, 17), pudiendo rastrearse estilemas prerrománticos ante litteram desde la segunda mitad del XVIII, cuando surge una reacción contra el intelectualismo que valoraba el conocimiento y menospreciaba la sensibilidad como un clima nuevo que pretendía celebrar la imaginación y el sueño. Esta corriente, renovando las vías de expresión precedentes, dará lugar a lo que se vienen considerando manifestaciones románticas propiamente dichas.

${ }^{97}$ Opera seria en dos actos de Giovanni Pacini sobre libreto de Andrea Leone Tottola, estrenada en el teatro San Carlo de Nápoles el 19-Xl-1825, cuyos decorados -obra de Antonio Niccolini (sobre este autor véase MANCINI, F: Scenografia Napoletana dell'Ottocento: Antonio Niccolini e il neoclassico. Napoli: Banca Sannitica, 1980)-parecieron servir de inspiración Pierre-LucCharles Ciceri para la escena del Vesubio de La muette de Portici.

${ }^{\$}$ Grand Opéra en cinco actos de D. F. E. Auber sobre libreto de E. Scribe y G. Delavigne, estrenada el el Théâtre de l'Opéra de paris (Salle Le Peletier) el 29-II-1828).

\$9 Melodramma sacro en tres actos con libreto de A. L. Tottola sobre texto de Francesco Ringhieri, estrenado en el Teatro San Carlo de Nápoles el 5-HII-1818 (1 $1^{\mathrm{a}}$ versión)/7-III-1819 (2a versión) y ampliada a cuatro actos como Moïse et le Pharaon por V. J. E. de Jouy y L. Balocchi para su estreno en la Opéra de Paris el 26-III-1827. 


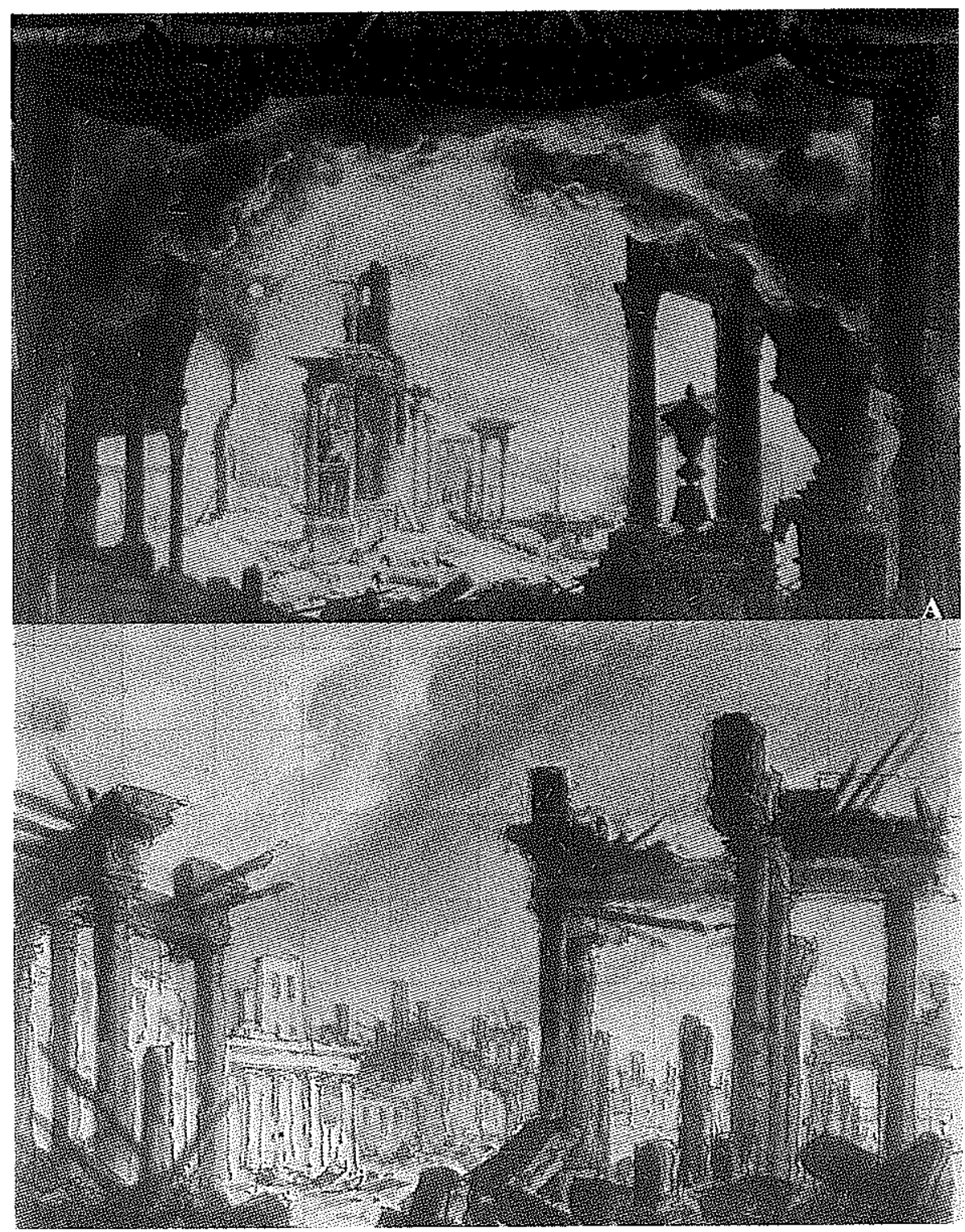

6. A Rossini: Le Siege de Corinthe. Pierre-Luc-Charles Ciceri: ' Ruinas de Corinto' (Acto III, c.9. Paris. Académie Royale de Musique, Salle le Peletier. 9-X-1826). Paris, Bibliotheque de lopéra.

B Verdi: Attila. Giuseppe Bertoja: 'Piazza di Aquileja' (Prólogo, c.1. Venezia. Teatro la Fenice. 17-III-1846). Venezia, Civico Museo Correr 
donde los estragos finales del asedio (realizados mediante una mutación a vista) componen una escena procelosa que, a decir de Jean Cabourg, emparenta con la que un día abriria el Otello de Verdi ${ }^{101}$, o incluso, a nivel de mera referencia iconográfica, la desoladora imagen de la ciudad arrasada de Corinto podria relacionarse con el aliento estético -compartiendo impostación visual, naturalmente actualizada- que animará en 1846 el comienzo de Attila (Prólogo, c1), cuando se muestra la asolada plaza de Aquilea en el diseño de Giuseppe Bertoja para el estreno de la obra. (FIG. 6)

Resulta revelador el hecho de que la escena del Attila antes mencionada se presente cuando la ciudad ya ha sido reducida a ruinas y no durante su devastación. Ello responde a que los expedientes de carácter 'orroroso' se van sosegando a lo largo del siglo a favor de otras correspondencias escenográficas entre fenómenos naturales y pasiones humanas ${ }^{102}$.

En cuanto a la pintura de historia, se han evidenciado numerosas conexiones entre ciertos estereotipos del imaginario escénico y la producción contemporánea de dicho género artístico, enormemente pujante a lo largo del siglo, ofreciendo la posibilidad de establecer lo que se podría definir como influencias reciprocas en sistemas afines ${ }^{103}$. La atención al dato verificable y perceptible en la reconstrucción de las escenas representadas se convirtió, en este tipo de cuadros, "en el objetivo principal, asi como también en garantía de éxito popular ante un público acostumbrado a ver sobre los escenarios de la época a personas vivas que cantaban y representaban dramas históricos", evidenciando un tono claramente teatral, un

\footnotetext{
${ }^{100}$ Versión francesa del Maometto Secondo (libreto de C. della Valle; estrenado en el Teatro San Carlo de Nápoles el 3-XII-1820), con libreto de L. Balocchi y A. Soumet, estrenada en la Opéra de Paris (Saile le Peletier) el 9-X-1826.

${ }^{101}$ CABOURG, J.: "'Le siège de Corinthe'. Livret intégral en français. Commentaire musical et littéraire". En Rossini. Le Siège de Corinthe (Maometto II) L'Avant Scène Opéra 81 (1985), págs. 27-63: 63

:02 Una correspondencia que podría retrotraerse, en otro plano, a las "arias de símil" o de "contraste interior" barrocas, donde la contraposición entre el estado de ánimo del personaje y un aspecto de la naturaleza proporcionaba imágenes circunscritas fundamentalmente al plano retórico, manifestándose a través del texto, la vocalidad del personaje y un acompañamiento orquestal ilustrativo (cfr. BUCCIARELLI, M.: Italian Opera and European Theatre 1680-1720. Publs. de la Fundación Pietro Antonio Locatelli. Amsterdam-Cremona: Brepols, 2000, págs. 65 y ss.). Ahora, sin embargo, no se tratará de comparar metafóricamente ambos términos, sino de identificarlos reproduciendo una atmósfera comprometida con la temperatura expresiva de la escena en cuestión o con el acontecer de la situación narrativa.

${ }^{103}$ Tomamos el término de Matteucci; aunque referido a otro ámbito cronológico parece perfectamente aplicable al argumento de las presentes líneas. MATTEUCCI, A. M.: "Architettura e grande decorazione: reciproche influenze in sistemi affini", en L'Arte del Settecento emiliano: architettura, scenografia, pittura di paesaggio (A. M. Mateucci, D. Lenzi, W. Bergamini, G. C. Cavalli, R. Grandi, A. Ottani Cavina y E. Riccòmini (coords.), Catalogo della X Biennale d'Arte Antica, Bologna: Museo Civico 8 settembre-25 novembre 1979, Bologna, Edizioni Alfa, 1980, págs. 3-92, especilmente la pág. 20.
} 
paralelo pictórico de la fusión dramática del sonido y la acción en una ópera de Verdi... ${ }^{104}$. De hecho la crítica teatral francesa, por ejemplo, abunda en invitaciones a los lectores a comparar la escenografia y la pintura, siendo Théophile Gautier un buen exponente.

El academicismo instrumentalizado de la pintura oficial de historia conoció una gran divulgación a escala internacional en la segunda mitad del XIX. Por ejemplo el coleccionismo privado norteamericano se interesó inmediatamente por estas obras ${ }^{105}$; en nuestro país, sin ir más lejos, la Ilustración Española y Americana publicó desde la década de 1870 numerosas obras contemporáneas de origen francés, italiano o germánico testimonio de toda la ampulosidad pompier ${ }^{106}$. El diccionario Larousse define pompier

par allusion aux personnages casqués que l'on voit dans leurs compositions, des artistes qui traitent, sans originalité de conception ni de facture, des sujets empruntés à l'Antiquité gréco-romaine. Par extension se dit des artistes pratiquant l'académisme. Se dit des litterateurs qui traitent des sujets rebattus, emploient de nombreux lieux communs, etc., et donc le style est emphatique et prétentieux ${ }^{107}$.

Se trata sin embargo de un adjetivo equivoco ${ }^{108}$ que define una estética oficializada, de corte retórico y con frecuentes efusiones sensualistas verificadas a través del gusto por la riqueza de las imágenes, el aparato (no inmune a la voluptuosidad) y el preciosismo virtuoso ${ }^{109}$, en un estilo y maneras fieles a la ortodoxia

${ }^{104}$ Cfr.: ROSENBLUM, R. y JANSON, H.: W. EI arte del siglo XIX. Akal/Arte y Estética 28. Madrid: Akal editores, 1992, págs. 319-320.

${ }^{105}$ La consulta de obras como SHINN, E.: The Art Treasures of America (Philadelphia: G. Barrie, 1880) constata largamente este hecho, pues entre los fondos reseñados aparecen insistentemente los nombres de los más conspicuos exponentes del academicismo pompier.

${ }^{106}$ Cfr.: REYERO, C.: La pintura de Historia en España. Cuademos Arte Cátedra 26. Madrid: Ediciones Cátedra, 1989, pág. 102.

${ }^{107}$ Dictionnaire Larousse. Paris: Librairie Larousse, 1963 (VIII): ad vocem. Trad. cast.: Dícese de los artistas, y de las obras por ellos realizadas, que se caracterizan por la falta de originalidad, o que caen en la vulgaridad y el adocenamiento. (Originalmente se dijo de las obras pictóricas cuyo tema aludía a la antigüedad grecorromana y en la que figuraban personajes con casco.). Por extensión, dícese de los artistas que practican con excesivo rigor el academicismo y de los escritores de estilo enfático y pedante que usan temas manidos y emplean numerosos lugares comunes, Gran Enciclopedia Larousse. Barcelona: Planeta s.a., 1967(VIII): ad vocem.

${ }^{108}$ MAGARIÑOS, J. M. "Meissonier, un centenario de formato menor". Boletín del Museo del Prado XIII-31 (1992), págs. 77-83, 80.

${ }^{109}$ Vid.: LECHARNY, L.-M.: L'Art pompier. Que sais-je? 3392. Paris: Presses Universitaires de France, 1998; RITZENTHALER, C.: L'École des BeauX-Arts du XIXe siècle: les pompiers. Paris: Mayer, 1987; SEGRE, M.: L'Art comme institution. L'École des BeauX-Arts: XIXème-XXème siècle. Cachan: Ed. de I'ENS-Cachan, 1993; SEGRE, M.: L'École des BeauX-Arts: XIXème-XXème siècle. Paris-Montréal: l'Harmattan, 1998. 
clasicista italiana"10. Con relación al argumento que nos ocupa, podria citarse como ejemplo del prestigio del molde clásico el hecho de que Verdi tuviera en mente los frescos rafaelescos de la 'Estancia de Heliodoro' vaticana"1 para la puesta en escena de Attila en La Fenice, de cuya escena del encuentro del Papa León I con el bárbaro solicitó abocetar una copia a Vincenzo Luccardi (distinguido pintor de historia italiano ${ }^{12}$ ): fammi dunque due segni colla penna, poi spiegami colle parole ed i numeri i colori del vestiario; sopra tutto ho bisogno dell'aconciattura della testa $(\ldots)^{173}$.

Destinado en principio a la pintura académica de historia francesa, este apelativo parece extenderse, por sincronia, a la estética por su medio desarrollada y asumida por otras naciones $y$ otros dominios artísticos pues, tal y como ha indicado Celebonovic, se trata de una expresión artística poco estudiada que, más allá de criterios formales $^{114}$, atestigua una adscripción psicosocial "entièrement lié aux préoccupations d'un ou de plusieurs groupes sociaux bien définis": la burguesia en su acepción más amplia ${ }^{115}$. La critica actual ha evidenciado un cierto aroma "pompier" en Aida, un regusto que habia asomado anteriormente ya en ciertos pasajes de Don Carlos (aria de Eboli Au palais des fées..." Nel giardin del bello...) "116.

El propio Verdi relacionó el "carácter y el color" de esta escena (All -1865//-1867, e2) con aquella del 'boudoir' de Amneris (All, e2): "Non vi è azione, ma con un po'

\footnotetext{
110) Resulta muy interesante la evolución de ciertas pervivencias clasicistas en el siglo XIX, detectable en diferentes sectores de la expresión artística y que también encuentra afinidades en la realización del espectáculo lírico. Sin entrar en consideraciones de orden estrictamente musical parece poder rastrearse una sutil línea de continuidad que concurre desde varios frentes. Si desde el academicismo pompier del género de historia se facilita la adherencia de un cierto clasicismo formal -evidenciado, además de en la fidelidad a la verosimilitud, en la autoridad de la congruencia perspéctica como fundamento compositivo de la pintura de escena, desde el punto de vista textual el melodramma romántico se ha identificado con la "degradazione democratica e borghese del sublime tragico" (PORTINARI, F.: "Sulla struttura...", 548 y ss.).

"' Desde hace tiempo se atribuye la ejecución del episodio del 'Encuentro de Atila con León Magno' a la escuela de Rafael, debatiéndose la presumible autoría del joven Giulio Romano. En cualquier caso se excluye la mano de Rafael Sanzio en la factura de los hunos, que interesaba a Verdi. Cfr: DE VECCHI, M.: La obra pictórica completa de Rafael. Barcelona-Madrid: Noguer/Rizzoli Editores, 1968, pág. 108.

112 Cfr.: BÉNÉZIT, E. "Luccardi, Vincenzo". En vol V de Dictionnaire critique et documentaire des peintres, sculpteurs, dessinateurs et graveurs... (Paris: Librairie Gründ, 1966): ad vocem. tis Carta de Verdi a V. Luccardi (11-11-1846). En CONATI, M. La bottega della musica. Verdi e La Fenice. Milano: Il Saggiatore, 1983, 170-71.

114 Lo indererminado de esta despectiva calificación queda de manifiesto cuando se comprueba su ltilización para designar "el noventa por ciento largo de los artistas franceses entre David y el impresionismo y cuya única característica común parece ser su estado de indigencia científica", MAGARIÑOS, J. M.: "Unos dibujos de Henry Lehmann en la Biblioteca Nacional de Madrid". Archivo Español de Arte LXVIII-271 (1995), págs. 237-253, 253.

is CELEBONOVIC, A.: Peinture Kitsch ou réalisme bourgeois. L'Art pompier dans le monde. Paris: Seghers, 1974, págs. 13, 26 y 177.
}

176 BALDACCI, L.: "I libretti di Verdi"... Ob. cit, págs.117-118 
d'adresse si può sempre riuscire (...). Non vi è azione alcuna nel Don Carlos quando le dame aspettano la regina (...); nonostante, con quel piccolo coro e quella canzone che ha tanto carattere e colore (...) si è riuscito à fare una vera piccola scena. Qui [en Aidal pure bisogna fare una scena con un coro ben lirico, colle ancelle che abbigliano Amneris, e con una danza di moretti etiopi. Tanto el frivolo decorativismo de resabio moruno en la canción de la princesa española (acompañada por el paje Tebaldo tañendo una mandolina) como el sensualismo ornamental que rodea a la princesa egipcia (danza de los jóvenes esclavos -ejecutado por bailarinas-) parecen responder a la moda artística impuesta por la gran corriente pompier de la segunda mitad del XIX: io non disapprovo seguir la moda -confesó el maestro en una ocasión a Giulio Ricordi- perché bisogna essere del proprio tempo"nb.

El ascendiente de la pintura de historia cristalizará en la escenografia decimonónica no sólo por razón de esa ósmosis estilística habitual entre disciplinas contemporáneas, sino también merced a la participación directa de pintores señalados en las puestas en escena de ciertas obras y de ciertos teatros ${ }^{119}$, en cuyas competencias depositaba su confianza el mismo Verdi. Éste es el caso de Émile Perrin, quien, antes de ser director de l'Opéra de Paris se había distinguido como pintor de historia vinculado a los talleres de Gros y Delaroche ${ }^{120}$ y a quien el compositor, a propósito del proyecto de La Forza del Destino (antes de ser abandonado a favor de Don Carlos) escribia: je suis sûr, qu'avec un directeur aussi intelligent, énergique et actif que vous l'êtes, je suir sûr, dis-je que je me trouverai toujours complètement d'accord, et les choses marcheront régulièrement et carrément ${ }^{12 !}$.

También es el caso de Francesco Hayez, uno de los más reputados representantes del género de historia en Italia, comprometido en el estreno de 1 Lombardi ${ }^{122}$ y a cuya autoridad Verdi recurrió para que supervisara la propiedad de los figurines destinados al estreno de Macbeth en el florentino Teatro della Pergola (1847): il libretto terminato, e spero anche i figurini (...) che saran fatti bene, perchè ho mandato a prenderne diversi a Londra, ho fatto consultare da letterati di

11 Cit. por ALBERTI, L.: "Note sulla disposizione...". Ob. cit., pág. 141.

118 Carta de Verdi a G. Ricordi (26-XII-1885). En CELLA, F; RICORDI, M. y DI GREGORIO CASATI, M. (eds.): Carteggio Verdi-Ricordi 1882-1885... Ob. cit., págs. 248 n $343 .$.

I:9 MAZZOCCA, F: "Pittura e melodramma: 1828-1850". En GOZZOLI, M. C. y MAZZOCCA, F. (eds.): Hayez. Milano: Electa, 1983. Vid. asimismo MAZZOCCA, F: Hayez privato: arte e passioni nella Milano romantica. Archivi dell'Ottocento. Milano-Londra: U. Allemandi, 1997.

${ }_{120}$ BÉNÉZIT, E.: "Perrin, Émile". En vol VI de Dictionnaire critique et... Ob. cit., ad vocem.

${ }^{221}$ Cit. por GÜNTHER, U.: "La genèse de 'Don Carlos', opéra en cinq actes de Giuseppe Verdi, représenté pour la première fois à Paris le 11 mars 1867". Revue de Musicologie LVIII 1 (1972), pág. 32.

${ }^{122}$ Cfr.: PIERI, M.: "Opera e letteratura". En Teorie e tecniche. Immagini e fantasmi (Vol. VI de Storia dell'opera italiana, Parte II 'I Sistemi'. L. Bianconi y G. Pestelli (eds.). Torino: Società Italiana di Musicologia, Eđizioni di Torino, 1988), págs. 235-300, 285. 
primissimo ordine l'epoca e i costumi, e poi saranno esaminati da Hayez e dalli altri della Commisione $(. . .)^{123}$. Esta alusión a la "commisione" descubre, además, la estrecha vinculación de Hayez con los coliseos de Milán (especialmente con la Scala) a través de su cometido en la Accademia di Brera. Relacionadas ambas instituciones prácticamente desde su fundación ${ }^{124}$ a partir de la década de 1840 la Accademia creará una Commisione Artistica destinada a supervisar los bocetos y figurines para las óperas "scaligeras" y de la Canobbiana, proyectándose así los criterios rectores de la personalidad artística de autores como Hayez en las puestas en escena de la época ${ }^{125}$, que afectaron, entre otros, a sendas reposiciones de Alzira (1847) y Luisa Miller (1851), así como al estreno italiano de Giovanna de Guzman (Vêpres, 1856)

${ }^{12: 3}$ Carta de Verdi a Lanari (21-I-1847). En CESARI, G. y LUZIO, A. (eds.): I copialettere di Giuseppe Verdi. Commisione esecutiva per le onoranze a Giuseppe Verdi nel primo anniversario della nascita. Milano: Stucchi Ceretti, 1913 (reed. anast. Bologna: Arnaldo Forni, 1968), pág. 447. ROSEN, D. y PORTER, A. (eds.): Verdi's 'Macbeth'. A sourcebook. New York-London: W. W. Norton \& Company, 1984, pág. 33.

124 Cfr: RICC1, G.: Duecento anni alla Scala: la scenografia. Milano: Grafica Gutenberg Editrice, 1977 , págs. 7 y ss.

${ }^{12.5}$ Para más información sobre este punto véase GOZZOLI, M. C. y MAZZOCCA, F.: Hayez... Ob. cit.; MAZZOCCA, F.: "Pittura storica e melodramma: il caso di Hayez". En Scritti in onore di Nicola Mangini (A cura dell'Università degli Studi di di Venezia, Facoltà di Lettere e Filosofia, Dipartimento di Storia e Critica delle Arti. Quaderni di Venezia arti 2. Roma: Viella, 1994), págs. 55-60.

126 Cfr: AGOSTI, G. y CIAPPARELLI, P: "La Commisione Artistica dell'Accademia di Brera e gli allestimenti verdiani alla Scala alla metà dell'Ottocento". En La realizzazione... Ob. cit., págs. 215-229. 
